\title{
The Relationship Between Acute: Chronic Workload Ratios and Injury Risk in Sports: A Systematic Review
}

This article was published in the following Dove Press journal:

Open Access Journal of Sports Medicine

\author{
Danny Maupin (1) \\ Ben Schram (iD) ${ }^{2}$ \\ Elisa Canetti (iD ${ }^{2}$ \\ Robin Orr (iD ${ }^{2}$ \\ 'Faculty of Health Sciences and Medicine, \\ Bond University, Robina, QLD, Australia; \\ ${ }^{2}$ Tactical Research Unit, Bond University, \\ Robina, QLD, Australia
}

\begin{abstract}
Purpose: Low injury rates have previously been correlated with sporting team success, highlighting the importance of injury prevention programs. Recent methods, such as acute: chronic workload ratios (ACWR) have been developed in an attempt to predict and manage injury risk; however, the relation between these methods and injury risk is unclear. The aim of this systematic review was to identify and synthesize the key findings of studies that have investigated the relationship between ACWR and injury risk.

Methods: Included studies were critically appraised using the Downs and Black checklist, and a level of evidence was determined. Relevant data were extracted, tabulated, and synthesized.

Results: Twenty-seven studies were included for review and ranged in percentage quality scores from $48.2 \%$ to $64.3 \%$. Almost perfect interrater agreement $(\kappa=0.885)$ existed between raters. This review found a high variability between studies with different variables studied (total distance versus high speed running), as well as differences between ratios analyzed (1.50-1.80 versus $\geq 1.50$ ), and reference groups (a reference group of $0.80-1.20$ versus $\leq 0.85$ ).

Conclusion: Considering the high variability, it appears that utilizing ACWR for external (eg, total distance) and internal (eg, heart rate) loads may be related to injury risk. Calculating ACWR using exponentially weighted moving averages may potentially result in a more sensitive measure. There also appears to be a trend towards the ratios of $0.80-1.30$ demonstrating the lowest risk of injury. However, there may be issues with the ACWR method that must be addressed before it is confidently used to mitigate injury risk. Utilizing standardized approaches will allow for more objective conclusions to be drawn across multiple populations.
\end{abstract}

Keywords: injury prevention, training load, athletics

\section{Introduction}

In sport, overall team success has been previously correlated with lower injury rates during the course of a season. ${ }^{1}$ Due to this relationship, injury prediction and prevention have become key practices in the athletic domain to maximize success. ${ }^{1}$ Various methods of predicting and preventing injuries have been developed to reduce injury risk, including musculoskeletal screens ${ }^{2}$ and strength and conditioning programs. ${ }^{3}$ Another method of reducing injury risk that is being utilized more often, after a British Journal of Sports Medicine blog by Dr. John Orchard ${ }^{4}$ and further detailing by Dr. Tim Gabbett, ${ }^{5}$ is the concept of tracking training load. By tracking the training load of an athlete, the training stimulus can be adjusted to ensure minimal injury risk while concurrently improving fitness. ${ }^{5}$ This strategy has been gaining popularity in sports such as Australian Football League (AFL) and soccer due to its potential relationship with injury risk. ${ }^{5}$ As an example, high three-weekly total distances have been associated with higher rates of injury in AFL players $(\mathrm{OR}=5.50){ }^{6}$
Correspondence: Danny Maupin

2 Promethean Way, Robina, QLD 4226 ,

Australia

Tel +6I 0755955530

Fax +6I 75595 IIII

Email dmaupin@bond.edu.au 
Training load can be divided into two categories, external load (EL), defined as "any external stimulus applied to the athlete that is measured independently of their internal characteristics", or internal load (IL), which is "load measurable by assessing internal response factors within the biological system, which may be physiological, psychological, or other". ${ }^{7}$ EL can be measured using variables such as total distance run, or number of sprints, while IL can be analyzed from heart rate or subjective scales such as Rating of Perceived Exertion. ${ }^{7}$ While an individual may perform the same output (EL), their ability to respond to this output (IL) may differ. Utilizing both measures provides a comprehensive view on whether an individual is in a state of "readiness" and able to tolerate high loads, or in a state "fatigue" and potentially at risk of injury or decreased performance. $^{5}$ These loads can be analyzed using weekly or bi-weekly totals, or by examining weekly changes in training load. ${ }^{5}$ An important aspect to consider is that the rate of change in load may be more problematic than the absolute load experienced by an individual. ${ }^{5,8}$ This concept has led to the creation of Acute:Chronic Workload Ratios (ACWR) in attempt to calculate an athlete's ability to tolerate sudden changes in load. ${ }^{5,8}$

ACWRs are calculated by dividing the acute workload, total load over the last week, by the chronic workload, usually a rolling average of the last 3-6 weeks. ${ }^{5}$ For example, if the acute workload is higher than the chronic workload, the ratio will be greater than one and the injury risk may be higher, though some research suggests that ratios from 0.80 to 1.30 may have the lowest injury risk. ${ }^{5}$ If the chronic workload is higher, the ratio will be lower than 1, and there is potentially less risk of injury; however, a lack of progressive overload may impede fitness development. ${ }^{5}$ A similar method known as Training Stress Balance (TSB) has also been referenced in the literature, and is calculated using the same methodology but presented as a percentage rather than a ratio. ${ }^{9}$ It has been previously theorized that ratios between 0.80 and 1.30 will provide the lowest risk of injury, ${ }^{5}$ and while this number has been supported by individual studies, ${ }^{10,11}$ it remains to be seen if the entirety of research confirms this idea. Therefore, the aim of this systematic review was to identify, critically appraise, and synthesize key findings in the literature regarding ACWR to determine if a relationship exists with musculoskeletal injury risk in sports and, if so, which ratios may result in the lowest risk of injury.

\section{Materials and Methods}

\section{Search Strategy}

A systematic search of key databases was employed to identify and include relevant studies to inform this review. The databases searched included Pubmed, Embase, CINAHL, and SportsDiscus and were chosen based on their large number of peer-reviewed material in this research area. Search terms (Table 1) were carefully selected based on the re-occurring terms found during a preliminary review of relevant literature. Once these key search terms were identified, the search was conducted by the research team using the terms and databases outlined in Table 1. Database filters were used if available to avoid including studies not relevant to this review (eg, utilizing a "Human" filter to avoid capturing any animal studies).

After all studies were selected, duplicates were removed, and the remaining studies were screened by title and abstract for relevance. As is the case with all reviews, there was a potential for bias, such as search bias, duplication bias, inclusion criteria bias and selector bias. ${ }^{12}$ Numerous strategies were employed to minimize these biases, such as utilizing broad search terms to capture all studies and minimize search bias, while duplication bias was limited by removing all duplicates during the first step of screening. Lastly, objective inclusion and exclusion criteria (Table 2) were established prior to screening to limit selector and inclusion criteria bias. The entire search process is outlined in the PRISMA diagram ${ }^{13}$ (Figure 1).

\section{Quality Assessment}

A modified Downs and Black checklist was then used to critically appraise each included article. ${ }^{14}$ This checklist is a 27-question assessment that provides a grade on the methodological quality, as well as an outline of the strengths and weaknesses of a study. ${ }^{14}$ Due to the subjectivity of question 27, regarding statistical power, ${ }^{14}$ the Downs and Black checklist was modified for this review. This question was changed from its original six-point scale, to a two-point scale. This has previously been done in research in an effort to increase objectivity. ${ }^{14}$ If a sample size or power analysis was reported, one point was awarded, while zero points were awarded if the sample size or power analysis were not mentioned. This modification reduces the maximum possible points from the original 32, to 28 .

To minimize any bias, the Downs and Black critical appraisal was completed by two authors (DM \& BS) working individually and separately. Cohen's Kappa coefficient $(x)$ was then calculated to provide a level of interrater agreement. The Critical Appraisal Scores (CAS) were then finalized, by using the average of the two final scores, and studies were then graded using qualitative ratings proposed by Kennelly. ${ }^{15}$ As the Kennelly grading system was based on the original Downs and Black Scoring system of 32 points, it was converted to a percentage-based score to enable comparable 
Table I Databases and Relevant Search Terms

\begin{tabular}{|c|c|c|c|}
\hline Database & Search Terms & Filters & Results \\
\hline PubMed & 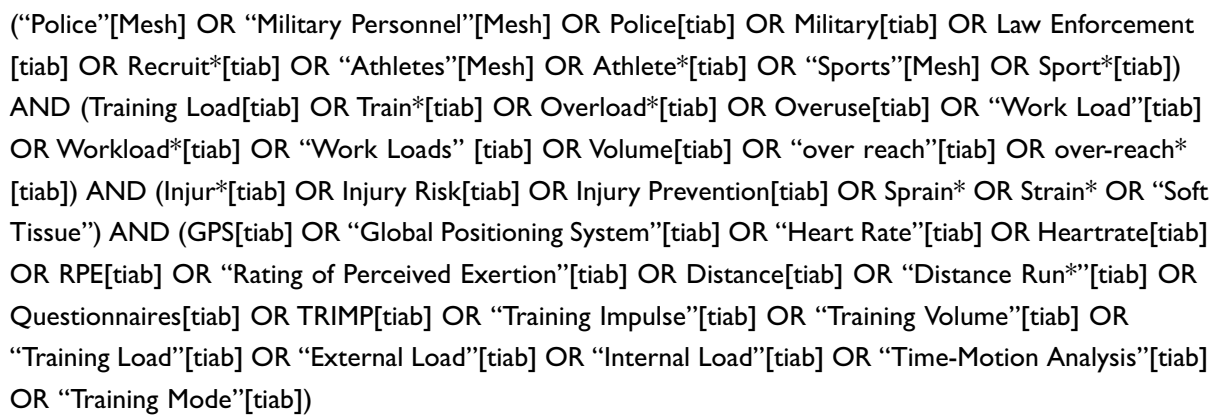 & $\begin{array}{l}\text { Human, } \\
\text { English }\end{array}$ & 1196 \\
\hline Embase & $\begin{array}{l}\text { (“Police”/exp OR “Soldier”/exp OR Police:ti,ab OR Military:ti,ab OR “Law Enforcement”:ti,ab OR Recruit*: } \\
\text { ti,ab OR “Athlete”/exp OR Athlete*:ti,ab OR “Sport”/exp OR Sport*:ti,ab) AND (“Training Load”:ti,ab OR } \\
\text { Train*:ti,ab OR Overload*:ti,ab OR Overuse:ti,ab OR “Work Load”:ti,ab OR Workload*:ti,ab OR “Work } \\
\text { Loads”:ti,ab OR Volume:ti,ab OR “over reach”:ti,ab OR over-reach*:ti,ab) AND (Injur*:ti,ab OR “Injury } \\
\text { Risk”:ti,ab OR “Injury Prevention”:ti,ab OR Sprain* OR Strain* OR “Soft Tissue”) AND (GPS:ti,ab OR } \\
\text { “Global Positioning System”:ti,ab OR “Heart Rate”:ti,ab OR Heartrate:ti,ab OR RPE:ti,ab OR “Rating of } \\
\text { Perceived Exertion”:ti,ab OR Distance:ti,ab OR “Distance Run*”:ti,ab OR Questionnaires:ti,ab OR TRIMP: } \\
\text { ti,ab OR “Training Impulse”:ti,ab OR “Training Volume”:ti,ab OR “Training Load”:ti,ab OR “External Load”: } \\
\text { ti,ab OR “Internal Load”:ti,ab OR “Time-Motion Analysis”:ti,ab OR “Training Mode”:ti,ab) }\end{array}$ & Human & 1946 \\
\hline CINAHL & 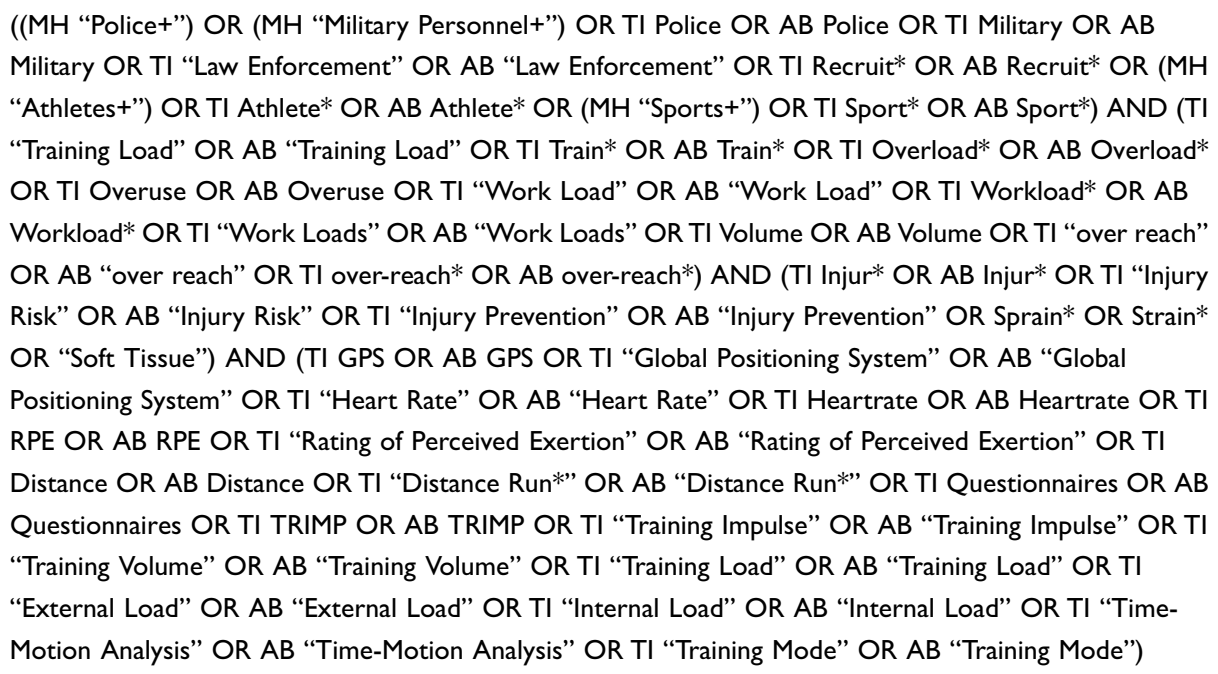 & English & 921 \\
\hline SportDiscus & 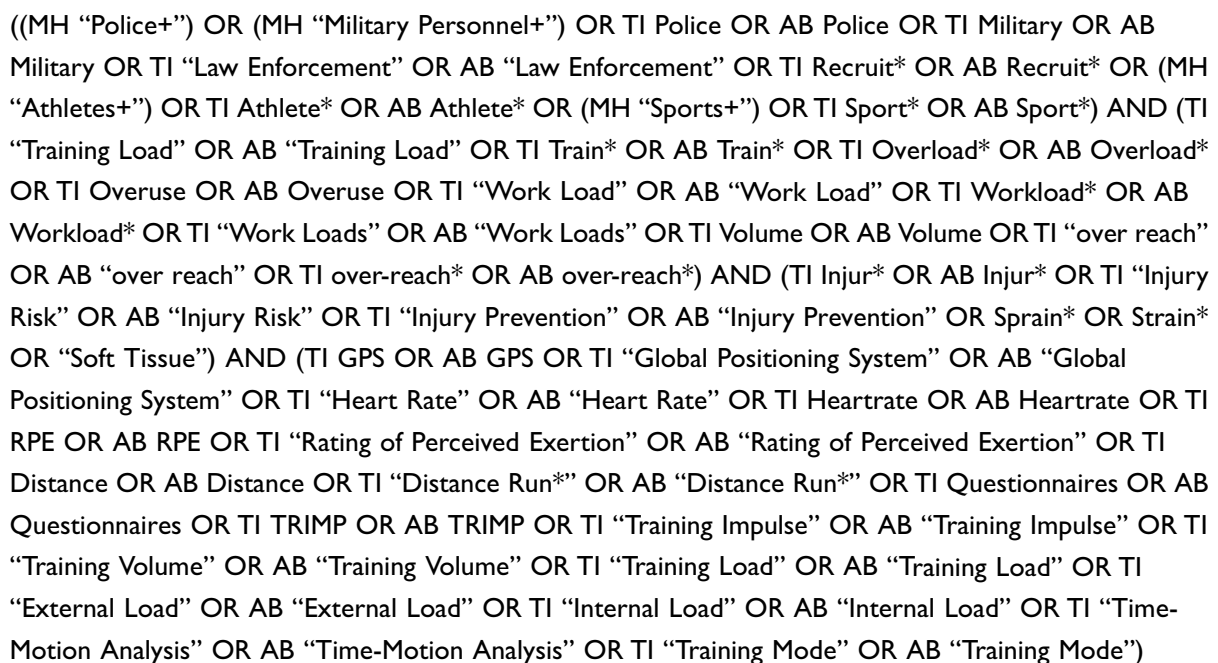 & None & 954 \\
\hline
\end{tabular}


Table 2 Inclusion and Exclusion Criteria and Examples of Excluded Studies

\begin{tabular}{|l|l|}
\hline Inclusion Criteria & Example/s \\
\hline Must contain sport or tactical population & Any study including sporting or tactical populations \\
\hline $\begin{array}{l}\text { Must examine acute:chronic workload ratios or training stress balance and } \\
\text { the relationship with injury risk }\end{array}$ & $\begin{array}{l}\text { Any study reporting the relationship between injury risk and } \\
\text { acute:chronic workload ratios }\end{array}$ \\
\hline Exclusion criteria & Example/s \\
\hline Not related to injury risk & Studies not discussing injury risk \\
\hline Youth population & Studies including participants under the age of I7 \\
\hline Systematic review & Studies presented as systematic reviews \\
\hline Not utilizing ACWR & Studies that did not utilize ACWR \\
\hline
\end{tabular}

grading. These percentage-based scores are $<45.4 \%$ signifying "poor" methodological quality, between $45.4 \%$ and $61.0 \%$ showing "fair" methodological quality, and $>61.0 \%$ demonstrating "good" methodological quality. ${ }^{15}$

\section{Data Extraction}

After the final studies were selected, appraised, and graded, key data were extracted. Data extracted included author and year of publication, population studied, method used to assess load (eg, ACWR or TSB), the reference value, variables examined, timeframes utilized, and associated risk.

\section{Data Analysis}

Comprehensive Meta-Analysis (Version 3.3) software program was used to create combined effect sizes of multiple outcomes from select studies to provide an overview of data. Studies were included if they examined ACWR and injury predictability without the effect of other variables, results were published in either odds ratios or relative risk (as these were the only present results that could be combined), and the study contained multiple outcomes in the ACWR ranges of $<0.80,0.80-1.30,1.30-2.00$, and $>2.00$. These ranges were chosen to compare results from outside the training "sweet spot" as proposed by Tim Gabbett. ${ }^{5}$

\section{Results}

\section{Search Results}

After the use of specific inclusion and exclusion criteria (Table 2), 27 studies were included for review.

\section{Critical Appraisal Results}

A Cohen's kappa analysis revealed an almost perfect agreement between raters $(\kappa=0.885) .{ }^{16}$ The average score of the studies was $59.7 \%$ indicating "fair" quality with the lowest score of $48.2 \%{ }^{17}$ and the highest score of $64.3 \% .^{18-23}$ These lower scores were likely due to the fact that the Downs and Black is typically used to grade randomized control trials, and most of the included studies were cohort studies. This resulted in consistently lower scores in areas of internal validity, specifically questions $14,15,19,23,24$, and 25. These questions were subsequently removed in an attempt to calculate a more representative score, resulting in increases of percentage quality scores, ranging from $61.4 \%{ }^{17}$ to $81.8 \%,{ }^{18-23}$ with a mean of $75.9 \%$, demonstrating "good" quality.

\section{Study Characteristics}

For general study characteristics, including population, variables examined, and method to assess load please refer to Table 3 .

The most common timeframe used was a 1-week acute training load and 4-week chronic training load. ${ }^{9-11,17,18,20-36}$ Other timeframes included a 3-day acute load and a 21 daychronic load, ${ }^{19}$ or varying timeframes. ${ }^{37-40}$ One study examined various timeframes for calculating $\mathrm{ACWR},{ }^{37}$ utilizing 2-9 days for acute loads, and chronic loads varying from 14 to 35 days, while the other study ranged from 1 to 2 weeks for acute loads, and 3-8 weeks for chronic loads, but only utilized the 1:4 week ratio for relationship to injury. ${ }^{38}$ Five studies utilized exponentially weighted moving averages (EWMA) for their calculation of $\mathrm{ACWR}^{17,27,29,36,39}$ and four articles studied a combination of ACWR and chronic workload. ${ }^{11,30,38,39}$ Lastly, one study examined ACWR in combination with recent lower limb injuries, ${ }^{36}$ while another evaluated the effects of fitness on the relationship between ACWR and injury risk. ${ }^{23}$ 


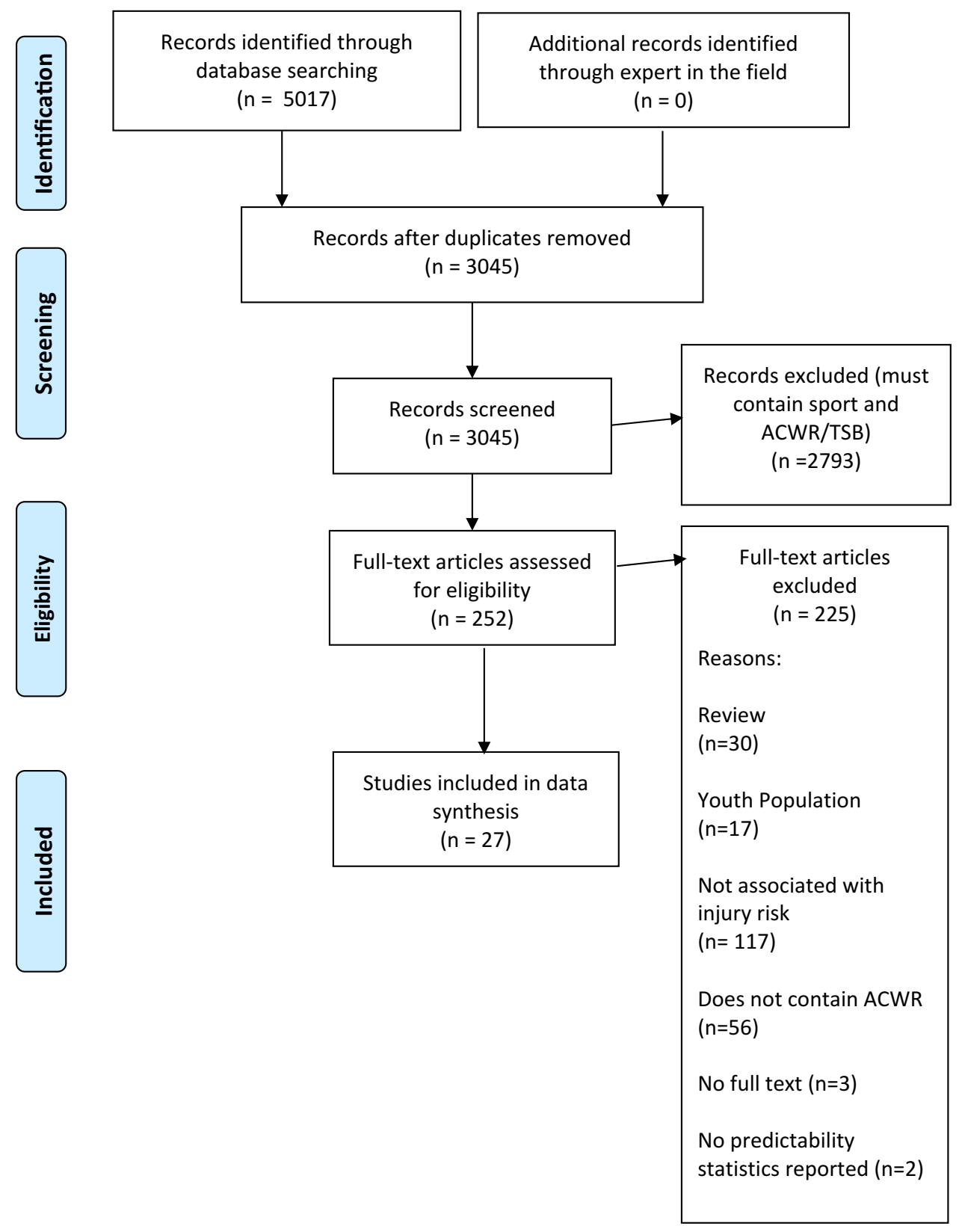

Figure I PRISMA flow chart.

\section{Association of External Loads and Injury Risks Total Distance}

All seven studies who reported total distance (TD) $)^{11,18,22,27,34,36,38}$ used ACWR. Three studies reported the ACWR of total distance and its relation to varying chronic workloads. ${ }^{11,30,38}$ Hulin et $\mathrm{al}^{18}$ found that an ACWR of 1.23-1.61 combined with short recovery ( $<7$ days between matches) increased injury risk compared to an ACWR of 1.02-1.22 ( $R R=2.88)$. In addition, it was also found that $\mathrm{ACWR} \geq 1.62$ combined with short recovery further increased injury risk relative to ACWR of $1.02-1.22(\mathrm{RR}=5.80)$ and $0.67-0.86(\mathrm{RR}=3.41) .{ }^{18}$ Even with longer recovery $(\geq 7$ days between matches), it was found that $\mathrm{ACWR} \geq 1.50$ still increased injury risk $(\mathrm{RR}=4.46)$ compared to an ACWR of $1.10-2.10 .^{18}$

Murray et $\mathrm{al}^{27}$ found that an ACWR using TD $>2.00$ increased chance of injury compared to a range 1.00-1.49 both during the pre-season $(\mathrm{RR}=8.41)$, and in-season $(\mathrm{RR}=6.52)$. This study ${ }^{27}$ also utilized EWMA-based ACWR and found that the same ratio using this method increased the relative risks to 8.74 and 21.28 , respectively. Similarly, another study by Murray et $\mathrm{al}^{22}$ found a TD ACWR $>2.00$ in-season also lead to a higher injury risk in the current week compared to ACWRs of $<0.49(\mathrm{RR}=7.98)$ 
Table 3 Characteristics of Included Studies

\begin{tabular}{|c|c|c|c|c|c|c|c|}
\hline Sport & References & $\begin{array}{l}\text { External } \\
\text { Load }\end{array}$ & References & $\begin{array}{l}\text { Internal } \\
\text { Load }\end{array}$ & References & Method & References \\
\hline AFL & {$[9,22,27,30,32,37,40]$} & Total & $\begin{array}{l}{[10,11,18,19,22,25-} \\
27,30,34,36-39]\end{array}$ & Total & $\begin{array}{l}{[9,10,17,20,21,23-26,28-} \\
33,35-38,40]\end{array}$ & ACWR & $\begin{array}{l}{[11,17-} \\
23,25-40]\end{array}$ \\
\hline Soccer & {$[19,20,25,26,33-35]$} & TD & {$[11,18,22,27,30,34,36,38]$} & & & & \\
\hline Rugby League & {$[11,18,34]$} & $\begin{array}{l}\text { Distance at } \\
\text { varying speed }\end{array}$ & {$[19,22,25,27,34,36-38]$} & sRPE & $\begin{array}{l}{[9,10,17,20,21,23-} \\
26,28,30,32,33,35-38,40]\end{array}$ & & \\
\hline Gaelic Football & {$[21]$} & $\begin{array}{l}\text { Change in } \\
\text { Acceleration }\end{array}$ & {$[22,27]$} & & & & \\
\hline Rugby Union & [24] & $\begin{array}{l}\text { Acceleration } \\
\text { Efforts }\end{array}$ & {$[25,34]$} & HRV & [29] & TSB & {$[9,10,24]$} \\
\hline Basketball & [28] & $\begin{array}{l}\text { Deceleration } \\
\text { Efforts }\end{array}$ & {$[25,34]$} & & & & \\
\hline Cross-Fit & [29] & $\begin{array}{l}\text { Distance- } \\
\text { Load }\end{array}$ & [37] & $\begin{array}{l}\text { Mood/sleep/ } \\
\text { stress }\end{array}$ & [3I] & & \\
\hline Cricket & {$[10]$} & $\begin{array}{l}\text { Sessions per } \\
\text { week }\end{array}$ & [26] & & & & \\
\hline American Football & [39] & $\begin{array}{l}\text { Bowls per } \\
\text { week }\end{array}$ & [10] & & & & \\
\hline Hurling & [23] & & & & & & \\
\hline Various & [3I] & & & & & & \\
\hline Endurance Sports & {$[17]$} & & & & & & \\
\hline
\end{tabular}

Abbreviations: AFL, Australian Football League; TD, total distance; sRPE, session rating of perceived exertion; HRV, heart rate variability; ACWR, acute:chronic workload ratio; TSB, training stress balance.

and $0.50-0.99(\mathrm{RR}=5.04)$. This same ratio increased risk of injury in the next week both during pre-season $(R R=4.87)$ and in-season $(\mathrm{RR}=5.49)$ when compared to an ACWR of $1.00-1.49 .^{22}$ The study by Cummins et al also demonstrated a significant relationship between $\mathrm{TD}$ and injury risk $(\mathrm{AUC}=0.580, p=0.09) .{ }^{34}$

Esmaeili et al $^{36}$ compared ACWR and EWMA-based ACWR for TD, and later combined these results with previous leg injuries. This article found that using EWMA-based ACWR demonstrated increases in hazard ratios (HR) (HR range from 21.0 to 6.80), compared to ACWR on its own (HR range from 0.92 to 2.40), and that the combination of a recent leg injury lead to higher hazard ratios for both methods (EWMA-based ACWR HR=16.00, ACWR HR=5.80). ${ }^{36}$

Stares et $\mathrm{al}^{38}$ examined various ACWR for TD in combination with chronic loads of other variables, and found that in comparison to an ACWR of 0.90-1.20 with a high 4-week chronic sprint distance (272-368m), an ACWR ranging from 1.50 to 1.80 combined with a very low 4 -week chronic sprint distance load $(<190 \mathrm{~m})$ lead to increases in injury risk 7 $(R R=3.31), 14 \quad(R R=3.00)$, and 21 days later $(R R=2.52)$. However, there was no significant increase 28 days later $(\mathrm{RR}=2.36) .{ }^{38}$ This same study also found an ACWR of 0.00-0.03 for TD combined with low 4-week chronic TD $(18,834-20,892 \mathrm{~m})$ further increased injury risk 7 days later $(\mathrm{RR}=8.19)$ compared to chronic sprint distance, but had no significant impact $14(\mathrm{RR}=5.49), 21(\mathrm{RR}=4.16)$ or 28 days later $(\mathrm{RR}=3.16)$ when compared to an ACWR 0.90-1.20 and a high 4-week chronic TD $(20892-22762 \mathrm{~m}){ }^{38}$

Colby et a ${ }^{30}$ reported, compared to ACWR range of 0.99 to 1.08 , ranges of $<0.88$ (IRR=1.17), 1.08-1.21 (IRR=1.37), and $>1.21(\mathrm{IRR}=1.53)$ resulted in higher incidence of injury, while $0.88-0.99$ (IRR $=0.60)$ resulted in a lower incidence when using TD. This same study found that when compared to an above average chronic TD load ( $81694 \mathrm{~m}$ over 4 weeks) and moderate ACWR $(0.99-1.08)$ a low chronic TD $(<81694 \mathrm{~m})$ and very high ACWR $(>1.21)$ were likely to increase injury risk with an incidence rate ratio (IRR) of $2.60 .{ }^{30}$ These findings are similar 
to those found by Stares et al, ${ }^{38}$ with both studies suggesting a low chronic load may increase injury risk. ${ }^{30}$

Hulin et $\mathrm{al}^{11}$ tracked load across the current week, the next week, and over a 2-week average utilizing ACWR (calculated through TD) to assess its relation to injury. The ACWR was divided into very low $(\leq 0.30$ current week and next week; $\leq 0.45$ 2-week average), low (0.31-0.66; 0.46$0.74)$, moderate-low (0.67-1.02; 0.71-1.01), moderate (1.03-1.38; 1.02-1.30), moderate-high (1.39-1.74; 1.31$1.58)$, high $(1.75-2.10 ; 1.59-1.87)$ and very high $(\geq 2.11$; $\geq 1.88$ ) categories. ${ }^{11}$ These values were found to have relative risks ranging from 0.0 (very low 2-week average) to 16.7 (very high current week and 2-week average) when compared to all other ACWR ranges. ${ }^{11}$ This study also examined the effects of the same categories and their 2week average compared to low $(<16095 \mathrm{~m})$ and high (>16095m) chronic workloads. ${ }^{11}$ When combined with low chronic workloads, relative risk ranged from 0.00 (very low ACWR) to 18.20 (very high ACWR), while the combination with high chronic workloads lead to relative risk values ranging from 0.00 (very low ACWR) to 28.60 (very high ACWR). ${ }^{11}$ However, these were not linear increases as moderate-low in both low $(R R=10.0)$ and high $(\mathrm{RR}=5.90)$ chronic workloads had a higher relative risk compared to a moderate ACWR in low $(\mathrm{RR}=9.30)$ and high $(\mathrm{RR}=6.20)$ chronic workloads. ${ }^{11}$ This contrasts with the results reported by Stares et al ${ }^{38}$ and Colby et $\mathrm{al}^{30}$ as ACWR combined low chronic workload was associated with similar or lower injury risk than ACWR combined with high chronic workload, except in the moderate ranges.

\section{Total Distance and Speed}

While multiple studies utilized distance at various speeds as a variable, their definitions of these speeds varied. ${ }^{19,22,25,27,30,34,36-38}$ For example, one study states high speed running (HSR) ranges from 18.01 to $24.00 \mathrm{~km} / \mathrm{h},{ }^{27}$ while another study stated HSR is anything greater than $14.40 \mathrm{~km} / \mathrm{h} .{ }^{19}$ In the study by Murray et al, ${ }^{27}$ an ACWR of 2.00 with HSR (18.01-24.00 km/h) increased injury risk relative to an ACWR ranging from 1.00 to $1.49(\mathrm{RR}=4.66)$. In this same study, the same ACWR comparison with medium speed running (MSR) $(6.00-18.00 \mathrm{~km} / \mathrm{h})$ was found to further increase injury risk both in-season $(R R=18.19)$ and pre-season $(\mathrm{RR}=6.03) .{ }^{27}$ In the study Murray, Gabbett, Townshend, Hulin, McLellan ${ }^{22}$ low speed running (LSR) $(0.00-6.00 \mathrm{~km} /$ h) and MSR (6.01-18.00 km/h), with ACWR $>2.00$, increased injury risk in the next week when compared to ACWRs ranging from 0.50 to 0.99 and 1.00 to 1.49 with $\mathrm{RR}$ ranging from 7.21 to $10.98 .^{22}$ In addition, it was found that an HSR running (18.01-24.00 km/h) ACWR of 2.00 increased injury risk both in the current and next week when compared to ACWRs of $0.50-0.99$ and 1.00-1.49, though to a lesser extent $(\mathrm{RR}=4.36-9.63)^{22}$

In the study by Jasper et al, ${ }^{25}$ an ACWR of $>1.18$ in regards to HSR $(>20 \mathrm{~km} / \mathrm{h})$ increased the odds of injury $(\mathrm{OR}=1.71)$ compared to an ACWR of $<0.79$. Likewise, Malone et $\mathrm{al}^{19}$ found that HSR $(>14.14 \mathrm{~km} / \mathrm{h})$ ACWRs $\geq 0.85$ increased the chance of injury with odds ratios ranging from 1.20 to 3.02 , when compared to a ratio of $\leq 0.85$. This study also found that sprint distance $(>19.8$ $\mathrm{km} / \mathrm{h}$ ) ACWRs $>0.70$ increased an athlete's odds of injury $(\mathrm{OR}=1.15-5.00)$ compared to ratios $\leq 0.70 .{ }^{19}$ The exception to this is an ACWR of $0.71-0.85$ which decreased injury risk ( $\mathrm{OR}=0.85)$, though the authors of this study did not present a potential explanation. ${ }^{19}$ It should also be noted that this study used a different timeframe than most other studies presented in this article, utilizing 3 days for acute workload instead of 7 days and 21 days for chronic workload instead of 28 days, to calculate their ratio.

Colby et $\mathrm{al}^{30}$ reported that sprint distance (SD) (>75\% players maximum speed) was associated with a player's injury risk. Compared to a reference value of 0.99-1.08, ACWR ranges of $<0.67 \quad(\mathrm{IRR}=1.83), \quad 1.13-1.40$ $(\mathrm{IRR}=1.06)$, and $>1.40 \quad(\mathrm{IRR}=1.90)$ resulted in higher injury incidence, while a range of $0.67-0.93(\mathrm{IRR}=0.99)$ resulted in a lower injury incidence.

Stares et $\mathrm{al}^{38}$ compared sprint distance ( $>75 \%$ max speed) in the presence of high chronic workload (272-368m) and an ACWR ranging from 0.90 to 1.20 to various ACWRs and very low or low chronic sRPE, sprint distance, and total distance, workloads. This study found that these ratios either increased relative injury risk with RR ranging from 1.94 to 8.19 or had no statistically significant effect, with $\mathrm{RR}$ ranging from 1.47 to $5.49 .^{38}$ In the study by Cummins et $\mathrm{al}^{34} \mathrm{a}$ statistically non-significant relationship was found between both HSR $(>20 \mathrm{~km} / \mathrm{h})(\mathrm{AUC}=0.504, p=0.205)$ and very HSR $(>25 \mathrm{~km} / \mathrm{h})(\mathrm{AUC}=0.543, p=0.205)$.

Esmaeili et $\mathrm{al}^{36}$ compared EWMA ACWR to ACWR using HSR $(>4.17 \mathrm{~m} / \mathrm{s})$ and found that EWMA ACWR resulted in higher $\mathrm{HR}$ (HR range from 1.59 to 4.60) compared to ACWR (HR range from 0.67 to 1.37). Combining recent leg injuries in the comparison led to a higher HR for both EWMA ACWR $(\mathrm{HR}=5.70)$ and $\operatorname{ACWR}(\mathrm{HR}=4.60)$. 
Carey et $\mathrm{al}^{37}$ examined both HSR $(>24 \mathrm{~km} / \mathrm{h})$ and MSR $(18-24 \mathrm{~km} / \mathrm{h})$. This study compared various daily ACWR (acute period ranging from 2 to 9 days; chronic 14, $18,21,24,28,32$, and 35 days), and examined the relative injury risk of ratios outside the range of $0.80-1.20 .^{37}$ It was found that using utilizing a timeframe of 5:14 days was likely to show increase injury risk $(\mathrm{R} R=2.74)$, while a timeframe of 5:24 days may show a smaller increase $(\mathrm{RR}=2.49)$ during HSR. ${ }^{37}$ Regarding MSR it was found that a timeframe of 3:28 days would show an increase in injury risk $(\mathrm{RR}=2.59)$, while other timeframes, $3: 21$ days $(R R=2.43)$, and 3:32 days $(R R=2.24)$ showed smaller increases in injury risk. ${ }^{37}$ The timeframe of 5:14 days was also used for MSR running, but unlike HSR, this timeframe showed a smaller increase $(R R=2.18)$ in injury risk. $^{37}$

\section{Player Load}

Five studies reported player load, which is derived from accelerometer acceleration, ${ }^{41}$ and ACWR. ${ }^{22,27,34,36,39}$ The first study found that an ACWR $>2.00$ increased current week injury risk during the season when compared to an ACWR ranging from 0.50 to $0.99(\mathrm{RR}=6.27) .{ }^{22}$ When compared to an ACWR ranging from 1.00 to 1.49 , an ACWR $>2.00$ lead to a similar increase in injury risk occurring in the next week in-season $(\mathrm{RR}=5.80)$, and a greater injury risk during pre-season $(\mathrm{RR}=12.46){ }^{22}$ This same comparison also showed an increased risk of injury in the current week during the season $(\mathrm{RR}=7.72) .{ }^{22}$ In the second study, an ACWR of 2.00 was compared to range of $1.00-1.49$ utilizing both rolling averages and EWMA. ${ }^{27}$ An ACWR of 2.00 using rolling averages lead to a relative injury risk of 5.87 during the season. ${ }^{27}$ Calculating the ACWR by using EWMA resulted in higher relative injury risk in season $(\mathrm{RR}=13.43)$ and during pre-season $(\mathrm{RR}=9.53) .{ }^{27}$ Similarly, Esmaeili et $\mathrm{al}^{36}$ found using EWMA ACWR leads to higher HR (HR range from 1.92 to 6.80) compared to ACWR (HR range from 0.84 to 2.20). The combination of player load and recent leg injuries led to higher HR for both EWMA ACWR $(\mathrm{HR}=16.00)$ and ACWR $(\mathrm{HR}=5.40) .{ }^{39}$

Sampson et $\mathrm{al}^{39}$ found that ACWR $>1.30$ led to a higher $\mathrm{RR}$ of injury compared to $<0.80(\mathrm{RR}=3.06)$ and $0.80-1.30$ $(R R=3.33)$. A similar finding was compared when the ACWR $>1.30$ was combined with a low 21-day chronic workload compared to $<0.80$ and low 21-day chronic workload $(R R=14.15)$ and $0.80-1.30$ with low 21-day chronic workload $(\mathrm{RR}=30.67) .{ }^{39}$ Lastly, though $0.80-1.30$ is thought to be the "sweet spot", 5 this ratio was found to have higher $\mathrm{RR}$ compared to $<0.80(\mathrm{RR}=2.59)$ and $>1.30(\mathrm{RR}=14.52)$ in combination with high 21-day chronic workloads. ${ }^{39}$ However, Cummins et al $^{34}$ found no statistically significant relationship between player load and injury ( $\mathrm{AUC}=0.561$, $p=0.155$ ).

\section{Other}

The ACWR of the number of acceleration and deceleration efforts was also studied. ${ }^{25,34}$ For acceleration efforts, an ACWR ranging from 0.87 to 1.22 decreased the chance of injury ( $\mathrm{OR}=0.39$ ) when compared to an ACWR of $<0.87$. $^{25}$ Likewise, an ACWR in deceleration efforts ranging from 0.86 to 1.12 also decreased injury risk $(\mathrm{OR}=0.38)$ compared to an ACWR of $<0.86 .{ }^{25}$ Cummins et al ${ }^{34}$ examined both measurements, and found that acceleration efforts (AUC $=0.605, \quad p=0.001$ ) and deceleration efforts (AUC $=0.581, p=0.037)$ had significant relationships with injury.

Cummins et $\mathrm{al}^{34}$ also evaluated relative distance $(\mathrm{m} /$ $\min$ ) and found that this measure had no significant relationship with injury (AUC $=0.492, p=0.811$ ).

Lastly, sessions per week ${ }^{26}$ and bowls per week ${ }^{10}$ were also studied. In sessions per week, it was reported that a higher ACWR occurred in injured athletes compared to non-injured (ES=0.83); however, no ratios were presented. ${ }^{26}$ Bowls per week was recorded using TSB. ${ }^{10}$ It was reported that a TSB $>200 \%$ had no relationship with injury risk compared to a TSB $\leq 100 \%$, but did increase risk injury risk in the next week when compared to a TSB $<49 \%(\mathrm{RR}=2.90)$ and a TSB ranging from $50 \%$ to $99 \%$ $(\mathrm{RR}=3.30) .{ }^{10}$

\section{Association of Internal Loads and Injury Risk Session Rating of Perceived Exertion}

Of the 18 articles that examined session Rating of Perceived Exertion (sRPE), 3 utilized TSB, ${ }^{9,10,24}$ while the other 15 implemented ACWR. ${ }^{17,20,21,23,25,26,28,30,32,33,35-38,40}$ Of the three studies that utilized TSB,,${ }^{9,10,24}$ one did not find any clear effects on injury risk after comparing a two standard deviation increase to the mean, ${ }^{24}$ while another found no relationship between a TSB $>200 \%$ and injury risk in the current week when compared to a TSB of $100 \% .{ }^{10}$ It was found, however, that a TSB $>100 \%$ increased injury risk in the next week compared to a TSB of $100 \%(R R=2.20) .{ }^{10}$ Hulin et $\mathrm{al}^{10}$ also discovered that, in comparison to a TSB of $50-99 \%$, both a TSB ranging from $150 \%$ to $199 \%$ 
$(\mathrm{RR}=2.10)$, and $>200 \%(\mathrm{RR}=4.50)$ increased risk of injury in the next week. The third study found that, when compared to a TSB of $<50 \%$, any TSB $>50 \%$ increased the odds of sustaining an injury, with odds ratios ranging from 1.17 to $4.00,{ }^{9}$ though it was not mentioned if this was during the current or next week. This was not a linear increase as a TSB of $150-199 \%$ had an odds ratio of 4.00 , while a TSB that was $>200 \%$ had an OR of $1.17 .^{9}$

With regards to SRPE and ACWR, Jasper et $\mathrm{al}^{25}$ found that when compared to an ACWR of $<0.85$, ACWRs of 0.87-1.12 and $>1.12$ decreased injury risk with an OR of 0.49 and 0.69 , respectively. During pre-season and inseason time periods, Malone, Owen, Newton, Mendes, Collins, Gabbett ${ }^{20}$ discovered that ACWRs of 1.00 to 1.25 may increase injury risk both pre-season $(\mathrm{OR}=0.68)$ and during season $(\mathrm{OR}=0.28)$ when compared to an ACWR of $\leq 0.85$. Similarly, a ratio of $0.85-1.00$ may also decrease injury risk during pre-season when compared to $\leq 0.85(\mathrm{OR}=0.95)$, though it may increase injury risk in season $(\mathrm{OR}=1.05) .{ }^{20}$ However, $\mathrm{ACWRs} \geq 1.50$ may increase injury risk during pre-season $(\mathrm{OR}=3.03)$ and in season $(\mathrm{OR}=2.33) .{ }^{20}$ In the study by Malone, Roe, Doran, Gabbett, Collins, ${ }^{21}$ ACWR $\geq 1.00$ led to ORs ranging from 0.88 to 5.33 when compared to an ACWR of 1.00. This same study also found that first-year Gaelic football players were at higher odds of sustaining an injury when compared to seventh-year players when the ACWR was $\geq 1.50$. $^{21}$ The authors of this study commented that this may be due to first-year players have a lower prior training history compared to the more experience players. $^{21}$ Utilizing the same ACWR, it was discovered that secondand third-year players $(\mathrm{OR}=0.20)$ and fourth- to sixth-year players $(\mathrm{OR}=0.24)$ were at less odds of sustaining an injury compared seventh-year players, suggesting a bell curve regarding player experience and injury risk.

McCall et al, ${ }^{26}$ utilizing sRPE, compared injured and non-injured players and found that a higher ACWR contributed a small to moderate effect size on injury $(\mathrm{ES}=0.45)$. In a similar fashion, Weiss et $\mathrm{al}^{28}$ discovered that ACWRs outside the range of 1.0-1.49 resulted in higher injury rates, ranging from 1.4 to 1.7 times more players injured. Carey et $\mathrm{al}^{37}$ also studied sRPE utilizing the same methods mentioned in the previous section. This study found that utilizing a timeframe of 9:18 days showed an increase in injury risk $(\mathrm{RR}=1.97)$, while a timeframe of 9:28 days showed a slightly less increase in risk of injury $(\mathrm{RR}=1.69) .{ }^{37} \mathrm{McCall}$ et $\mathrm{al}^{40}$ also utilized various timeframes and found that only 1:3 week and 1:4 week
ACWR were associated with injury risk. Though it should be noted only three comparisons resulted in statistically significant outcomes: ACWR range of 0.97-1.38 compared to $0.60-0.97(\mathrm{RR}=1.68),>1.38$ compared to $0.60-$ $0.97(\mathrm{RR}=2.13)$, and $>1.42$ compared to $0.59-0.97$ $(\mathrm{RR}=1.90){ }^{40}$

Colby et $\mathrm{al}^{30}$ examined sRPE and found that, compared to an ACWR range of 1.02-1.14, an ACWR $>1.30$ decreased injury incidence $(\mathrm{IRR}=0.93)$ while ranges of $<0.86$ $(\mathrm{IRR}=1.38), \quad 0.86-1.02 \quad(\mathrm{IRR}=1.02) \quad$ and $\quad 1.14-1.30$ $(I R R=1.01)$ increased injury incidence. This reported relationship does not follow the other variables reported in this and other studies, with the highest ACWR range demonstrating the lowest injury risk. In another study by Colby et al, ${ }^{32}$ it was found that three or more exposures to ACWR $>1.37$ over 2 weeks led to an increased injury incidence ( $I R R=1.93)$ compare to less than 3 exposures over the same time frame. Johnston et al utilized EWMA ACWR in a study of endurance runners and found that, compared to a ratio of $<0.80$, ratios of 0.80-1.30 $(\mathrm{HR}=1.21), \quad 1.30-1.50 \quad(\mathrm{HR}=1.34)$, and $>1.50$ $(\mathrm{HR}=2.15)$ led to high chances of injury.

Not every study found positive associations between ACWR with sRPE and injury risk. The study by RayaGonzalez et $\mathrm{al}^{33}$ found no association between ACWR and injury $(\mathrm{OR}=0.16)$, though it was unclear which ratios were being compared. Similarly, Delecroix et $\mathrm{al}^{35}$ found conflicting evidence with only ACWR $>0.85$ leading to statistically significant result when compared to ACWR $<0.85(\mathrm{RR}=1.31)$ when using the 1:4 week calculation method. This study did find statistically significant associations between $1: 3$ weeks $>1.30$ compared to $1: 3$ weeks $\leq 1.30(\mathrm{RR}=1.37), 1: 2$ weeks $\leq 0.85$ compared to $1: 2$ weeks $>0.85(\mathrm{RR}=1.80), 1: 2$ weeks $<0.85$ and $>1.25(\mathrm{RR}=1.55)$, $1: 1$ week $<0.85$ to $1: 1$ week $>0.85(\mathrm{RR}=1.94), 1: 1$ week $<1.25$ to $1: 1$ week $>1.25(\mathrm{RR}=1.68)$ and $1: 1$ week $<0.85$ and $>1.25(\mathrm{RR}=1.33){ }^{35}$

While most studies utilized sRPE on its own, Stares et $\mathrm{al}^{38}$ utilized ACWR of sRPE combined with very low chronic workloads of different variables (eg, sprint distance). These were then compared to an ACWR of 0.9-1.2 and a high chronic workload. This study discovered that in the presence of very low chronic workloads (distance, sprint distance, and sRPE), risk of injury increased 7, 14, 21, and 28 days later with $\mathrm{RR}$ ranging from 2.71 to 6.93 , similar to the results found using ELs. ${ }^{38}$ This study also examined an ACWR of 0.3-0.6 with a very low sRPE chronic workload and found that injury risks increase $7,14,21$, and 28 days later $(R R=2.15-2.38)$ compared to an ACWR of 0.90-1.20 and a 
high sRPE chronic workload. ${ }^{38}$ Colby et a ${ }^{30}$ also combined ACWR with a chronic load and, similar to Stares et al, ${ }^{38}$ found that a low chronic SRPE load $(<4660 \mathrm{AU})$ combined with a low ACWR (0.86-1.02) was likely to increase injury risk $(\mathrm{IRR}=2.52)$ when compared to an above average chronic sRPE load (4660 AU) and moderate ACWR (1.02-1.14). Malone et $\mathrm{al}^{23}$ combined sRPE with performance on fitness testing. This study demonstrates a trend that as individuals fitness decreases, measured by strength relative to bodyweight, and sprinting speed, the odds of injury increased. ${ }^{23}$ Lastly, the study by Esmaeili et $\mathrm{al}^{36}$ found that when combing ACWR calculated from SRPE and recent leg injuries the HR increased for both ACWR $(\mathrm{HR}=3.70)$ and EWMA $(H R=6.80)$ compared to not combination with leg injury (ACWR HR=2.80, EWMA ACWR HR=4.00).

\section{Other}

One study ${ }^{29}$ examined heart rate variability (HRV), the variation in time between resting heartbeats, and found that when comparing a normal ACWR combined with moderate log-transformed square root of the mean sum of the squared differences between R-R intervals ( $\mathrm{Ln}$ RMSSD) a high ACWR combined with a low Ln RMSSD lead to an increase in chance of injury $(\mathrm{RR}=2.61)$. The normal and high ACWR were calculated by utilizing within-individual z-scores which were parsed into tertiles resulting in z-scores of 0.31 to 0.41 for normal ACWR and $>0.41$ for high ACWR. ${ }^{29}$ Hamlin et $\mathrm{al}^{31}$ compared various IL measures and found that mood $(\mathrm{OR}=0.89)$, energy $(\mathrm{OR}=1.07)$, sleep duration $(\mathrm{OR}=0.94)$ and academic stress $(\mathrm{OR}=0.91)$ were significantly related to odds of injury in elite university athletes.

Please refer to Table 4 for an overview of the statistics from each study including confidence intervals and p-values where appropriate.

\section{Combined Effect Size}

Seven studies were analyzed to produce a combined effect size ${ }^{10,11,19-22,27}$ (Figure 2). Variables examined included TD, ${ }^{11,22,27}$ sRPE, ${ }^{10,20,21}$ HSR, ${ }^{19,22} \mathrm{PL}^{22}$ and MSR. ${ }^{22}$ The combined effect sizes show a trend for an ACWR range of $0.80-1.30$ being related to a lower injury risk. In terms of OR, ACWR greater than 2.0 showed a higher risk $(\mathrm{OR}=4.00,95 \% \mathrm{CI}=1.65-9.68)$, compared to a range of $1.30-2.00(\mathrm{OR}=1.69,95 \% \mathrm{CI}=0.67-4.30)$, and $0.80-1.30$ $(\mathrm{OR}=0.59,95 \% \mathrm{CI}=0.14-2.45$ and $1.65,95 \% \mathrm{CI}=1.51-$ 1.81). For RR, ACWR $>2.0$ resulted in RRs ranging from 3.91 to 8.90 , while $<0.8$ had a RR of 3.57 (95\%
$\mathrm{CI}=1.65-9.68)$ and $1.30-2.00$ was $11.51(95 \% \mathrm{CI}=5.57-$ 23.79). The range of 1.30-2.00 appears to be an outlier, possibly due to the study using all other ACWR as a reference value which included low ranges, such as $<0.30$. While this study ${ }^{11}$ was unable to create a combined effect size for ACWR $>2.00$, it does report a single result demonstrating a higher RR (16.7). No variable was present across all four ranges for comparison; however, two were included in three ranges (sRPE and TD). sRPE shows a higher combined OR in an ACWR greater than 2.00 $(\mathrm{OR}=4.00,95 \% \mathrm{CI}=1.65-9.68)$ compared to $1.30-2.00$ $(\mathrm{OR}=1.69,95 \% \mathrm{CI}=0.67-4.30)$ and $0.8-1.3 \quad(\mathrm{OR}=0.59$, 95\% CI $=0.14-2.45$ ), while TD shows a higher RR in the ACWR of $1.3-2.0(\mathrm{RR}=11.51,95 \% \mathrm{CI}=5.57-23.79)$, compared to greater than $2.0(\mathrm{RR}=5.73,95 \% \mathrm{CI}=3.42-9.59$ and $7.41,95 \% \mathrm{CI}=1.72-31.89)$ and $<0.8(\mathrm{RR}=3.57,95 \%$ $\mathrm{CI}=1.65-9.68)$.

\section{Discussion}

The aim of this systematic review was to identify, critically appraise, and synthesize key findings in the literature regarding ACWR and provide evidence for an ACWR that results in the lowest injury risk. This review found the literature was generally of "good" quality. Furthermore, the research included high variability in points of reference, ACWR ranges, and variables tested. It appears that utilizing ACWR with external and internal loads may relate to injury risk, with EWMA ACWR potentially resulting in a more sensitive measure; however, the high variability of the involved studies makes it difficult to be sure. There also appears to be a trend towards the ratios of 0.80 to 1.30 demonstrating the lowest risk of injury.

\section{External Loads}

There was high variability in the variables measured, reference groups and ACWR ranges. For example, while HSR was a relatively common variable studied the definitions varied between articles. One study defined HSR as anything greater than $20 \mathrm{~km} / \mathrm{hr},{ }^{25}$ while another study defined HSR as anything greater than $14.4 \mathrm{~km} / \mathrm{hr} .{ }^{19}$ With regards to reference groups, one study utilized a reference group of less than or equal to $0.85,{ }^{19}$ while another used $1.00-1.49 .{ }^{27}$ Given the notable variability between studies, systematic comparison and analysis is difficult. However, given the high number of statistically significant results across the range of studies ${ }^{10,11,18,19,22,25-27,30,37,38}$ of "good" quality, it is likely that utilizing ELs and ACWR may have a relationship with injury risk. While this article 
Table 4 Key Injury Predictability Data from Each Article

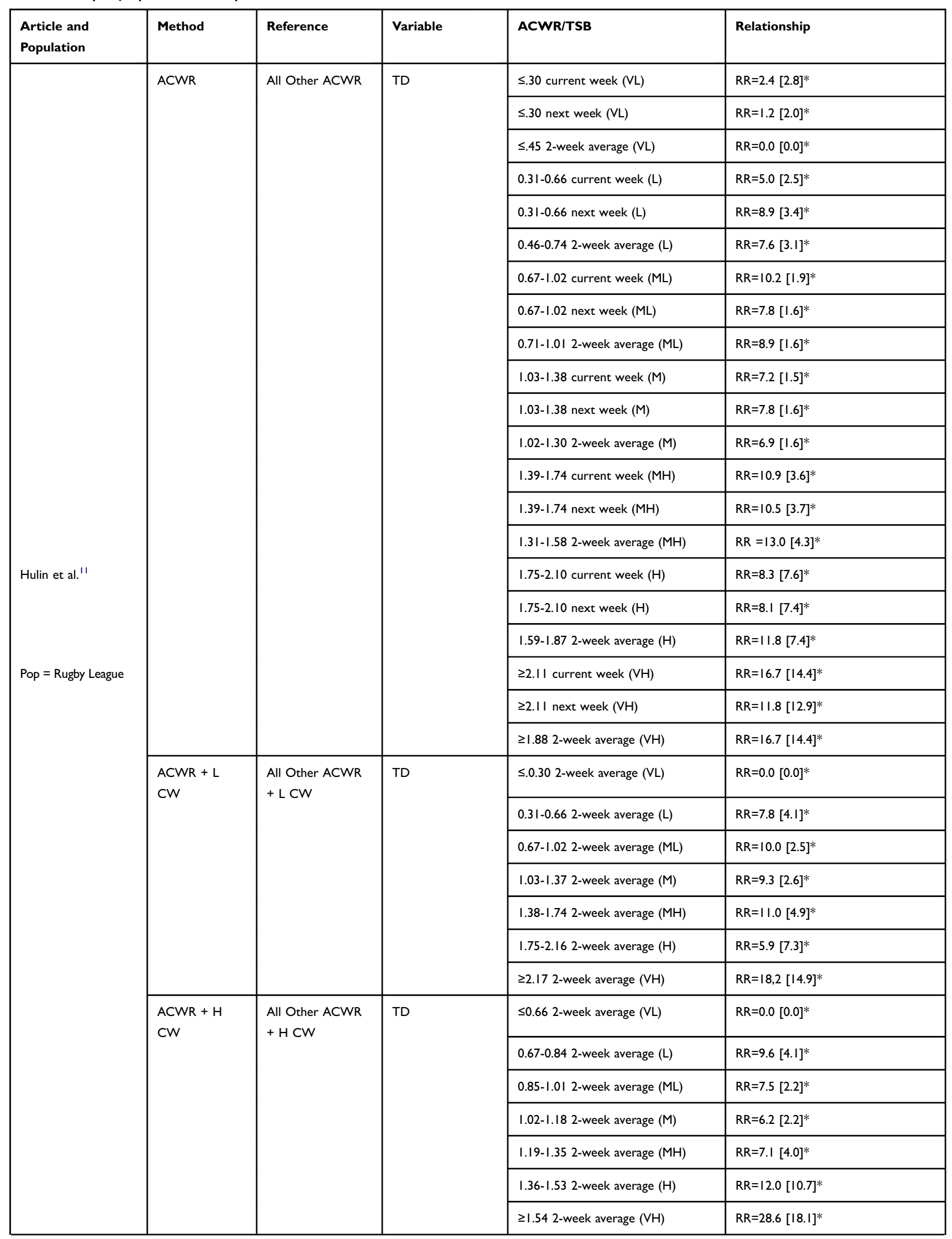

(Continued) 
Table 4 (Continued).

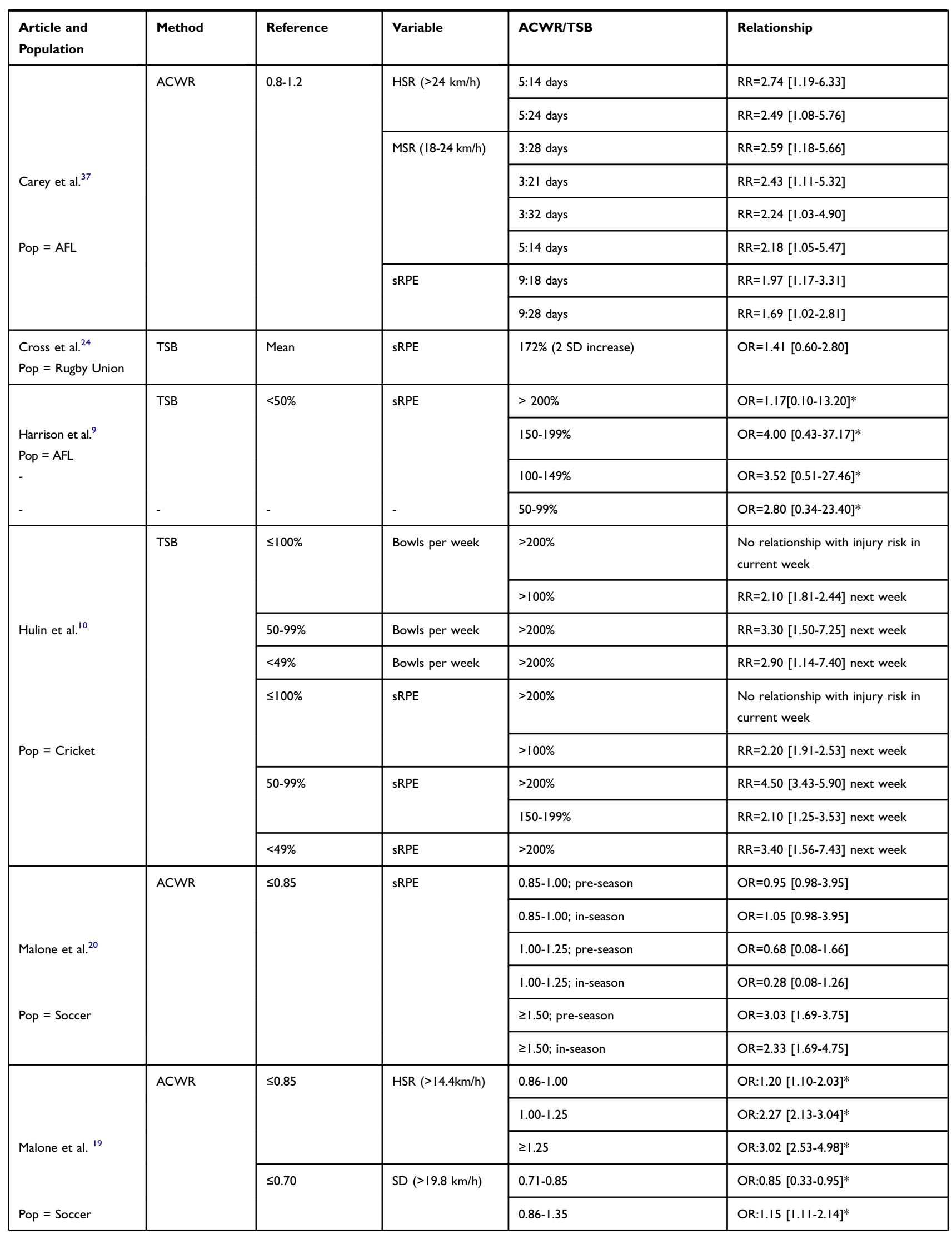

(Continued) 
Table 4 (Continued).

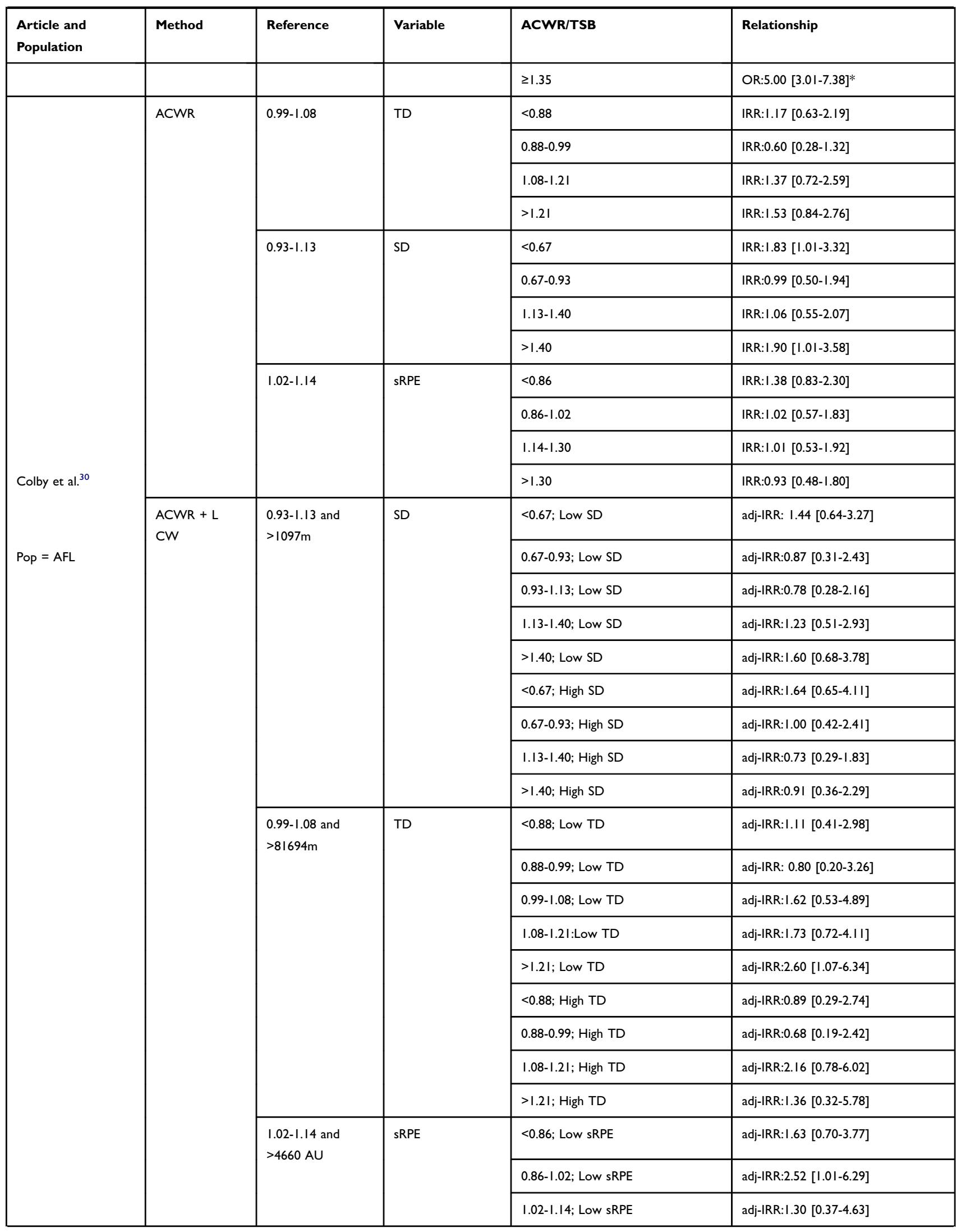

(Continued) 
Table 4 (Continued).

\begin{tabular}{|c|c|c|c|c|c|}
\hline $\begin{array}{l}\text { Article and } \\
\text { Population }\end{array}$ & Method & Reference & Variable & ACWR/TSB & Relationship \\
\hline & & & & I.I4-I.30; Low sRPE & adj-IRR:I.02 [0.44-2.34] \\
\hline & & & & $>1.30$; Low sRPE & adj-IRR:0.6I [0.26-1.45] \\
\hline & & & & $<0.86$; High sRPE & adj-IRR:0.86 [0.30-2.50] \\
\hline & & & & 0.82-1.02; High sRPE & adj-IRR:0.83 [0.34-2.04] \\
\hline & & & & I.I4-I.30; High sRPE & adj-IRR:0.67 [0.25-1.85] \\
\hline & & & & $>$ I.30: High sRPE & adj-IRR:0.62 [0.13-3.07] \\
\hline \multirow{7}{*}{ Malone et al. ${ }^{21}$} & \multirow[t]{13}{*}{ ACWR } & \multirow[t]{10}{*}{1.00} & \multirow[t]{10}{*}{ sRPE } & $\geq 2.00$; pre-season & $\mathrm{OR}=3.33[1.69-6.75]$ \\
\hline & & & & $\geq 2.00$; early in-season & OR:4.33 [1.69-6.75] \\
\hline & & & & 1.35-1.50; late in-season & OR:3.25 [1.69-7.5I] \\
\hline & & & & $\geq 2.00$; late in-season & OR:5.33 [1.69-6.75] \\
\hline & & & & $\geq 2.00$; total in-season & OR:3.33 [1.69-6.65] \\
\hline & & & & I.00-1.35; pre-season & $\mathrm{OR}=1.95[0.98-3.95]$ \\
\hline & & & & I.35-1.50; pre-season & $\mathrm{OR}=0.88[0.28-4.66]$ \\
\hline \multirow{6}{*}{$\begin{array}{l}\text { Pop = Gaelic } \\
\text { Football }\end{array}$} & & & & 1.00-1.35; early in-season & $\mathrm{OR}=1.95[0.98-3.95]$ \\
\hline & & & & 1.35-1.50; early in-season & $\mathrm{OR}=0.88[0.28-4.66]$ \\
\hline & & & & 1.00-1.35; late in-season & $\mathrm{OR}=2.95[0.98-3.95]$ \\
\hline & & \multirow[t]{3}{*}{$\geq 1.50$; 7th year } & \multirow[t]{3}{*}{ sRPE } & $\geq 1.50 ;$ Ist year & OR:2.22 [1.45-3.36] \\
\hline & & & & $\geq 1.50$; 2 nd- 3 rd year & OR:0.20 [0.04-0.78] \\
\hline & & & & $\geq 1.50$; 4th-6th year & OR:0.24 [0.06-0.80] \\
\hline \multirow{2}{*}{$\begin{array}{l}\text { McCall et al. }{ }^{26} \\
\text { Pop }=\text { Soccer }\end{array}$} & \multirow[t]{2}{*}{ ACWR } & $0.60-2.0$ & sRPE & $1.65-1.75$ & ES:0.45 [0.3I-0.87]* \\
\hline & & $0.90-1.10$ & $\#$ of sessions & $1.00-2.00$ & ES:0.83 [0.56-1.60]* \\
\hline \multirow{6}{*}{ Murray et al. ${ }^{27}$} & \multirow[t]{4}{*}{ ACWR } & \multirow[t]{4}{*}{$1.0-1.49$} & \multirow[t]{2}{*}{ TD } & $>2.0$; pre-season & RR:8.4I [1.09-64.93] \\
\hline & & & & $>2.0$; in-season & RR:6.52 [4.83-8.80] \\
\hline & & & $\begin{array}{l}\text { HSR }(|8.0|-24.00 \\
\mathrm{km} / \mathrm{h})\end{array}$ & $>2.0$; in-season & RR:4.66 [4.12-5.27] \\
\hline & & & Player Load & $>2.0$; in-season & RR:5.87 [4. 12-8.36] \\
\hline & \multirow{6}{*}{$\begin{array}{l}\text { EMWA } \\
\text { ACWR }\end{array}$} & \multirow[t]{6}{*}{$1.0-1.49$} & \multirow[t]{2}{*}{ TD } & $>2.0$; pre-season & RR:8.74 [7.35-10.39] \\
\hline & & & & $>2.0$; in-season & RR:21.28 [20.02-22.62] \\
\hline \multirow[t]{4}{*}{$\mathrm{Pop}=\mathrm{AFL}$} & & & \multirow{2}{*}{$\begin{array}{l}\text { MSR }(6.00- \\
18.00 \mathrm{~km} / \mathrm{h})\end{array}$} & $>2.0$; pre-season & $R R: 6.03[2.21-16.4]$ \\
\hline & & & & $>2.0$; in-season & RR:18.19 [17.17-19.27] \\
\hline & & & \multirow[t]{2}{*}{ Player Load } & $>2.0$; pre-season & RR:9.53 [5.31-17.1I] \\
\hline & & & & $>2.0$; in-season & RR:I3.43 [I2.75-|4.|4] \\
\hline \multirow[b]{2}{*}{ Hulin et al. ${ }^{18}$} & \multirow[t]{2}{*}{ ACWR } & \multirow[t]{2}{*}{$1.02-1.22$} & \multirow[t]{2}{*}{ TD } & I.23-1.6I; short recovery & $R R=2.88[0.97-8.55]^{*}$ \\
\hline & & & & $\geq 1.62 ;$ short recovery & $R R=5.80[1.75-19.2]^{*}$ \\
\hline
\end{tabular}

(Continued) 
Table 4 (Continued).

\begin{tabular}{|c|c|c|c|c|c|}
\hline $\begin{array}{l}\text { Article and } \\
\text { Population }\end{array}$ & Method & Reference & Variable & ACWR/TSB & Relationship \\
\hline \multirow[b]{2}{*}{ Pop $=$ Rugby League } & & $0.67-0.86$ & TD & $\geq 1.62$; short recovery & $R R=3.41[1 . \mid 7-9.91]^{*}$ \\
\hline & & $1.10-1.20$ & TD & $\geq 1.50$; long recovery & $\mathrm{RR}=4.46[0.91-21.91]^{*}$ \\
\hline \multirow{3}{*}{ Jaspers et al. ${ }^{25}$} & \multirow[t]{5}{*}{ ACWR } & $<0.79$ & HSR $(>20 \mathrm{~km} / \mathrm{h})$ & $>1.18$ & $\mathrm{OR}=1.71[1.08-3.26]^{*}$ \\
\hline & & $<0.87$ & $\begin{array}{l}\text { Acceleration } \\
\text { efforts }\end{array}$ & $0.85-1.12$ & $\mathrm{OR}=0.39[0.23-0.65]^{*}$ \\
\hline & & $<0.86$ & $\begin{array}{l}\text { Deceleration } \\
\text { efforts }\end{array}$ & $0.86-1.12$ & $\mathrm{OR}=0.38[0.20-0.72]^{*}$ \\
\hline \multirow[t]{2}{*}{ Pop $=$ Soccer } & & \multirow[t]{2}{*}{$<0.85$} & \multirow[t]{2}{*}{ sRPE } & $0.87-1.12$ & $\mathrm{OR}=0.49[0.24-\mathrm{I} .02]^{*}$ \\
\hline & & & & $>1.12$ & $\mathrm{OR}=0.69[0.42-1.13]^{*}$ \\
\hline \multirow{18}{*}{ Murray et al. ${ }^{22}$} & \multirow[t]{18}{*}{ ACWR } & \multirow[t]{2}{*}{$<0.49$} & TD & $>2.0$; in-season & RR:7.98 [5.86-10.88]* current week \\
\hline & & & $\begin{array}{l}\text { HSR }(I 8.01-24.00 \\
\mathrm{km} / \mathrm{h})\end{array}$ & $>2.0$; in-season & $\begin{array}{l}\text { RR:II.62 [10.04-I3.45]* current } \\
\text { week }\end{array}$ \\
\hline & & \multirow[t]{6}{*}{$0.50-0.99$} & TD & $>2.0$; in-season & RR:5.04 [4.16-6.1 I ]* current week \\
\hline & & & $\begin{array}{l}\text { LSR }(0.00-6.00 \\
\mathrm{km} / \mathrm{h})\end{array}$ & $>2.0$; in-season & RR:9.06 [7.78-10.56]* current week \\
\hline & & & $\begin{array}{l}\text { MSR }(6.01- \\
18.00 \mathrm{~km} / \mathrm{h})\end{array}$ & $>2.0$; in-season & $\begin{array}{l}\text { RR:I0.98 [10.73-| I .25]* current } \\
\text { week }\end{array}$ \\
\hline & & & $\begin{array}{l}\text { HSR }(18.01-24.00 \\
\mathrm{km} / \mathrm{h})\end{array}$ & $>2.0$; pre-season & RR:6.46 [4.63-9.02]* next week \\
\hline & & & $\begin{array}{l}\text { HSR }(|8.0|-24.00 \\
\mathrm{km} / \mathrm{h})\end{array}$ & $>2.0$; in-season & RR:9.63 [9.2I-10.07]* current week \\
\hline & & & Player Load & $>2.0$; in-season & RR:6.27 [5.62-6.00]* current week \\
\hline & & \multirow[t]{10}{*}{$1.00-1.49$} & \multirow[t]{2}{*}{ TD } & $>2.0$; pre-season & RR:4.87 [2.33-|0.2I]* next week \\
\hline & & & & $>2.0$; in-season & RR:5.49 [4.19-7.20]* next week \\
\hline & & & \multirow{2}{*}{$\begin{array}{l}\text { LSR }(0.00- \\
6.00 \mathrm{~km} / \mathrm{h})\end{array}$} & $>2.0$; pre-season & RR:8.29 [2.90-23.69]* next week \\
\hline & & & & $>2.0$; in-season & RR:7.25 [6.44-8.16]* next week \\
\hline & & & $\begin{array}{l}\text { MSR }(6.01- \\
18.00 \mathrm{~km} / \mathrm{h})\end{array}$ & $>2.0$; in-season & RR:7.21 [6.80-7.65]* next week \\
\hline & & & \multirow{2}{*}{$\begin{array}{l}\text { HSR }(18.0 \mathrm{I}-24.00 \\
\mathrm{km} / \mathrm{h})\end{array}$} & \multirow[t]{2}{*}{$>2.0$; in-season } & RR:6.54 [6.19-6.92]* current week \\
\hline & & & & & RR:4.36 [3.50-5.43]* next week \\
\hline & & & \multirow[t]{3}{*}{ Player Load } & $>2.0$; pre-season & RR:I2.46 [8.35-18.59]* next week \\
\hline & & & & $>2.0$; in-season & RR:7.72 [7.57-7.88]* current week \\
\hline & & & & & RR:5.80 [4.62-7.27]* next week \\
\hline & \multirow[t]{4}{*}{ ACWR } & \multirow{4}{*}{$\begin{array}{l}0.9-1.2, \text { High } \\
\text { Chronic Load }\end{array}$} & \multirow[t]{4}{*}{ sRPE } & \multirow[t]{4}{*}{ I.8-2.1, Very Low Chronic TD } & IRR:4.96; $p=0.007$ days later \\
\hline & & & & & IRR:5.67; $p=0.00$ I 4 days later \\
\hline & & & & & IRR:6.93; $\mathrm{p}=0.0021$ days later \\
\hline & & & & & IRR:4.89; $\mathrm{p}=0.0028$ days later \\
\hline
\end{tabular}

(Continued) 
Table 4 (Continued).

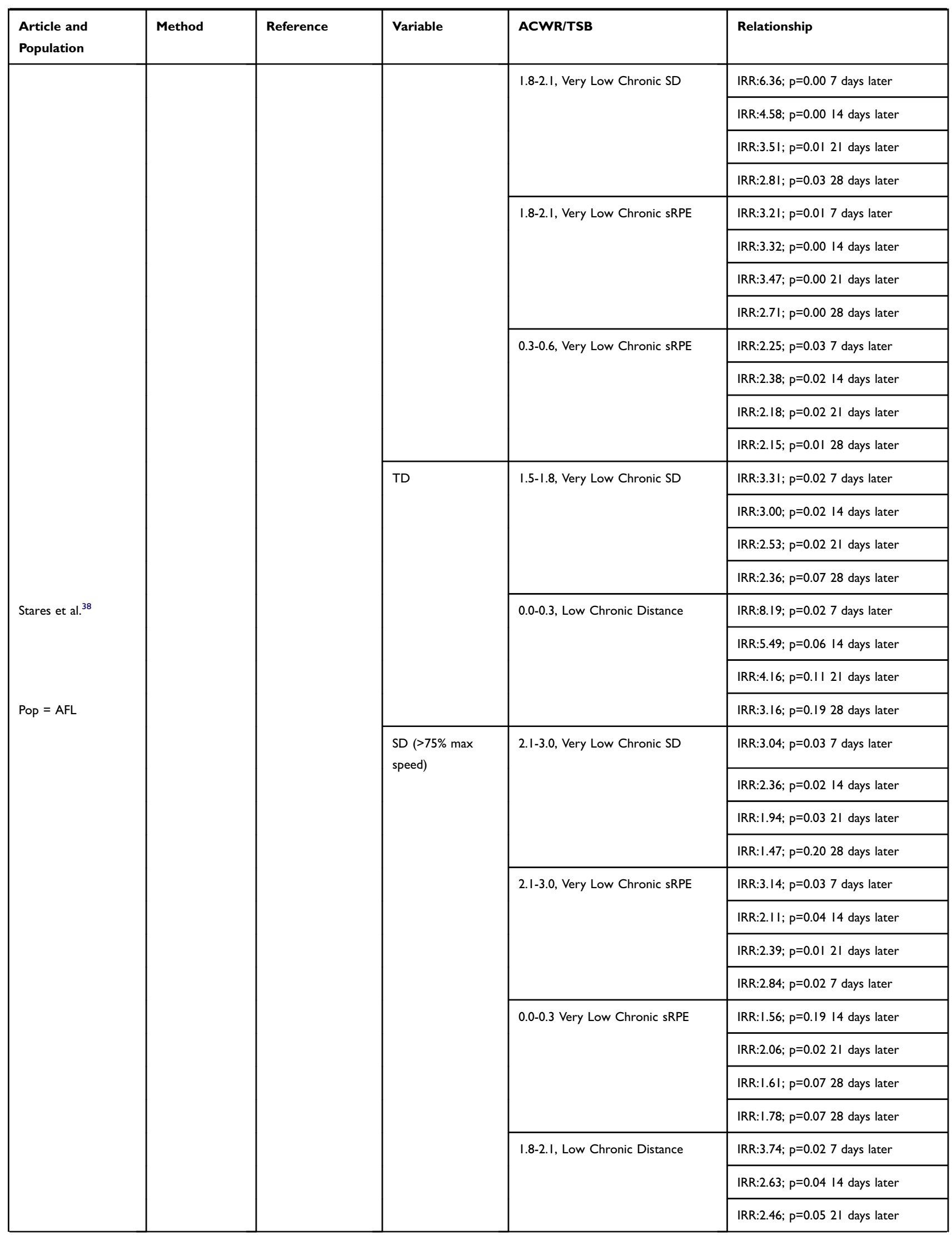

(Continued) 
Table 4 (Continued).

\begin{tabular}{|c|c|c|c|c|c|}
\hline $\begin{array}{l}\text { Article and } \\
\text { Population }\end{array}$ & Method & Reference & Variable & ACWR/TSB & Relationship \\
\hline & & & & & IRR:I.69; $p=0.2428$ days later \\
\hline & & & & 2.1-3.0, Low Chronic Distance & IRR:3.71; $p=0.037$ days later \\
\hline & & & & & IRR:3.9I; $p=0.0014$ days later \\
\hline & & & & & IRR:3.83; $p=0.0021$ days later \\
\hline & & & & & IRR:2.86; $\mathrm{p}=0.0128$ days later \\
\hline & & & & 2.1-3.0, Low Chronic Sprint & IRR:5. I I; $p=0.027$ days later \\
\hline & & & & & IRR:3.37; $\mathrm{p}=0.01 \quad 14$ days later \\
\hline & & & & & IRR:3.21; $p=0.0021$ days later \\
\hline & & & & & IRR:2.4I; $p=0.0328$ days later \\
\hline & ACWR & $1.0-1.49$ & sRPE & $\leq 0.5$ & I.5x more injured players $[0.30]^{\wedge}$ \\
\hline Weiss et al. ${ }^{28}$ & & & & 0.5 and 0.99 & I.4x more injured players $[0.25]^{\wedge}$ \\
\hline Pop $=$ Basketball & & & & $\geq 1.5$ & $1.7 x$ more injured players $[0.50]^{\wedge}$ \\
\hline $\begin{array}{l}\text { Williams et al. }{ }^{29} \\
\text { Pop }=\text { Cross-Fit }\end{array}$ & ACWR & $\begin{array}{l}\text { Normal' ACWR } \\
\text { and 'moderate' } \\
\text { LnRMSSW }\end{array}$ & HRV & High' ACWR and 'low' LnRMSDD & RR: 2.61 [1.38-4.93]* \\
\hline \multirow{15}{*}{ Malone et al..$^{23}$} & \multirow[t]{15}{*}{ ACWR } & All Other & sRPE & $0.90-1.30$ & Protective effect \\
\hline & & \multirow{3}{*}{$\begin{array}{l}>1.25 \text { and }>3.00 \\
\mathrm{~kg} / \mathrm{kg} \text { deadlift }\end{array}$} & \multirow[t]{3}{*}{ sRPE } & $>1.25$ and $2.50-2.90 \mathrm{~kg} / \mathrm{kg}$ deadlift & OR: 1.33 [1.10-1.59] \\
\hline & & & & $>1.25$ and $1.70-2.40 \mathrm{~kg} / \mathrm{kg}$ deadlift & OR: 2.48 [1.33-3.87] \\
\hline & & & & $>1.25$ and $1.00-1.70 \mathrm{~kg} / \mathrm{kg}$ deadlift & OR: $5.10[3.98-6.10]$ \\
\hline & & \multirow{3}{*}{$\begin{array}{l}>1.25 \text { and } 5 \mathrm{~m} \text { in } \\
<0.88 \text { seconds }\end{array}$} & \multirow[t]{3}{*}{ sRPE } & $>1.25$ and $5 \mathrm{~m}$ in $0.88-0.92$ seconds & OR: 2.1I [1.45-3.23] \\
\hline & & & & $>1.25$ and $5 \mathrm{~m}$ in $0.92-0.95$ seconds & OR: 3.23 [2.1I-4.12] \\
\hline & & & & $>1.25$ and $5 \mathrm{~m}$ in $>0.95$ seconds & OR: 3.98 [2.34-4.55] \\
\hline & & \multirow[t]{3}{*}{$\begin{array}{l}>1.25 \text { and } 10 \mathrm{~m} \text { in } \\
<1.75 \text { seconds }\end{array}$} & \multirow[t]{3}{*}{ sRPE } & $\begin{array}{l}>1.25 \text { and } 10 \mathrm{~m} \text { in } 1.75-1.78 \\
\text { seconds }\end{array}$ & OR: 1.87 [1.34-2.54] \\
\hline & & & & $\begin{array}{l}>1.25 \text { and } 10 \mathrm{~m} \text { in } 1.78-1.83 \\
\text { seconds }\end{array}$ & OR: 2.11 [I.45-3.II] \\
\hline & & & & $>1.25$ and $10 \mathrm{~m}$ in $>1.83$ seconds & OR: $2.78[1.32-3.14]$ \\
\hline & & \multirow[t]{3}{*}{$\begin{array}{l}>1.25 \text { and } 20 \mathrm{~m} \text { in } \\
<2.85 \text { seconds }\end{array}$} & \multirow[t]{3}{*}{ sRPE } & $\begin{array}{l}>1.25 \text { and } 20 \mathrm{~m} \text { in } 2.85-2.89 \\
\text { seconds }\end{array}$ & OR: $2.11[1.76-3.12]$ \\
\hline & & & & $\begin{array}{l}>1.25 \text { and } 20 \mathrm{~m} \text { in } 2.89-3.01 \\
\text { seconds }\end{array}$ & OR: $3.12[2.87-4.11]$ \\
\hline & & & & $>1.25$ and $20 \mathrm{~m}$ in $>3.01$ seconds & OR: 4.55 [2.12-4.98] \\
\hline & & \multirow[t]{2}{*}{$\begin{array}{l}>1.25 \text { and }<30 \\
\text { seconds RST }\end{array}$} & \multirow[t]{2}{*}{ sRPE } & $\begin{array}{l}>1.25 \text { and } 30.50-34.00 \text { seconds } \\
\text { RST }\end{array}$ & OR: $1.02[0.26-2.59]$ \\
\hline & & & & $\begin{array}{l}>1.25 \text { and } 34.50-36.00 \text { seconds } \\
\text { RST }\end{array}$ & OR: $2.48[1.33-3.87]$ \\
\hline
\end{tabular}

(Continued) 
Table 4 (Continued).

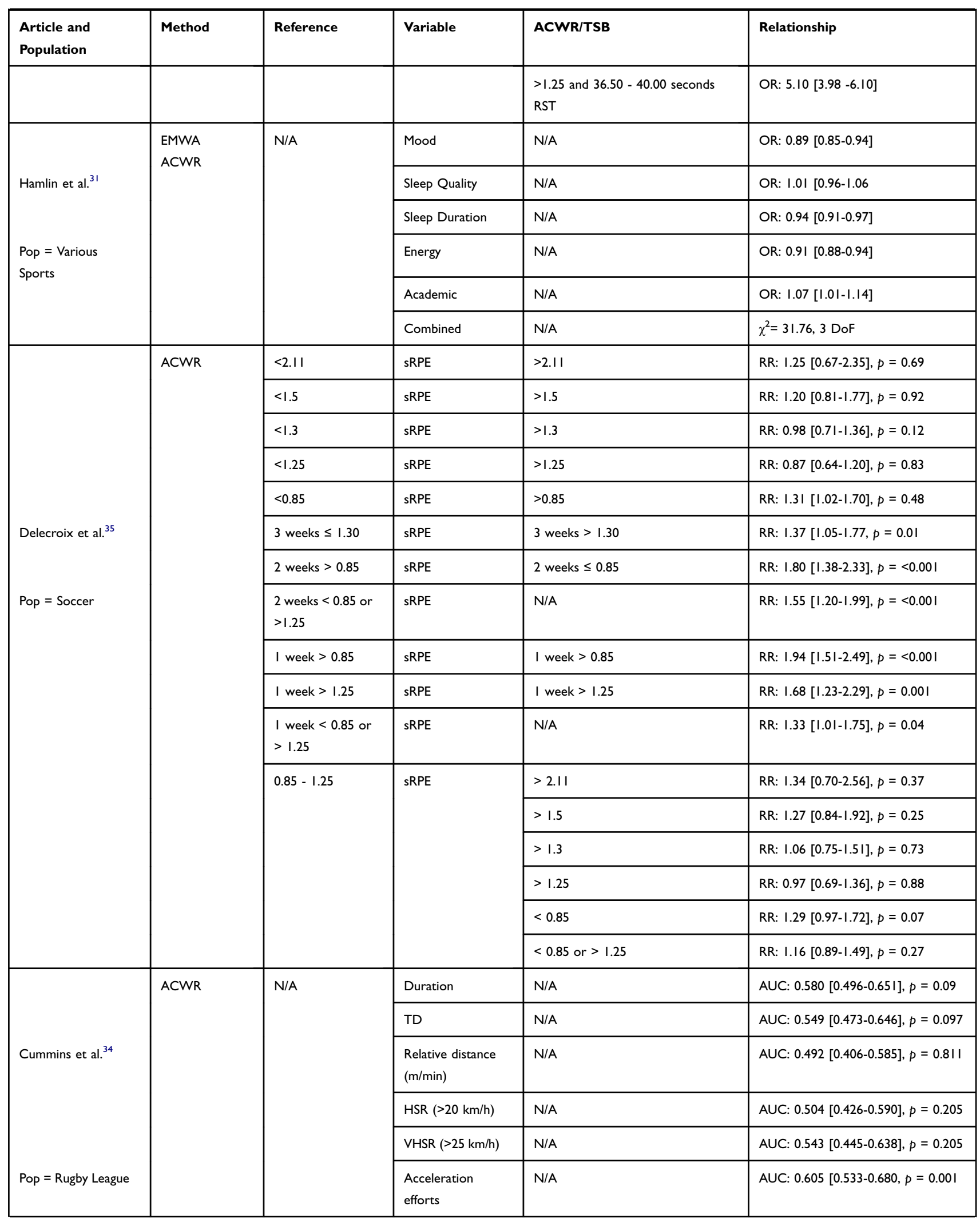

(Continued) 
Table 4 (Continued).

\begin{tabular}{|c|c|c|c|c|c|}
\hline $\begin{array}{l}\text { Article and } \\
\text { Population }\end{array}$ & Method & Reference & Variable & ACWR/TSB & Relationship \\
\hline & & & $\begin{array}{l}\text { Deceleration } \\
\text { efforts }\end{array}$ & N/A & AUC: $0.581[0.503-0.650], p=0.037$ \\
\hline & & & Player Load & N/A & AUC: $0.561[0.460-0.656], p=0.155$ \\
\hline & EMWA ACWR & $<0.80$ & sRPE & $0.80-1.30$ & HR: $1.21[1.01-1.44]$ \\
\hline $\begin{array}{l}\text { Raya-Gonzalez et al. }{ }^{33} \\
\text { Pop }=\text { Soccer }\end{array}$ & ACWR & Unknown & sRPE & Unknown & OR: $0.16[0.01-1.84]^{*}$ \\
\hline $\begin{array}{l}\text { Colby et al. }{ }^{32} \\
\text { Pop }=\text { AFL }\end{array}$ & ACWR & $\begin{array}{l}<3 \text { exposures to } \\
\text { ACWR }>1.37 \\
\text { over last } 2 \text { weeks }\end{array}$ & sRPE & $\begin{array}{l}\geq 3 \text { exposures to } A C W R>1.37 \\
\text { over last } 2 \text { weeks }\end{array}$ & Adj-IRR I.93 (I.|3-3.3I) \\
\hline Johnston et al. ${ }^{17}$ & \multirow{14}{*}{ ACWR } & \multirow{5}{*}{$\mathrm{I}: 4 ;<0.60$} & & $1.30-1.50$ & HR: $1.34[1.01-1.76$ \\
\hline $\begin{array}{l}\text { Pop = Endurance } \\
\text { Sports }\end{array}$ & & & & $>1.50$ & HR: 2.15 [1.04-4.44] \\
\hline \multirow{12}{*}{ McCall et al. ${ }^{40}$} & & & \multirow[t]{3}{*}{ sRPE } & $\mathrm{I}: 4 ; 0.60-0.97$ & RR: 0.88 [0.44-I.73] \\
\hline & & & & $\mathrm{I}: 4 ; 0.97-1.38$ & RR: I.47 [0.78-2.78 \\
\hline & & & & $\mathrm{I}: 4,>1.38$ & RR: $1.86[0.93-3.72]$ \\
\hline & & \multirow[t]{2}{*}{$\mathrm{I}: 4,0.60-0.97$} & \multirow[t]{2}{*}{ sRPE } & $\mathrm{I}: 4 ; 0.97-1.38$ & RR: $1.68[1.02-2.78]$ \\
\hline & & & & $\mathrm{I}: 4,>1.38$ & RR: $2.13[1.20-3.77]$ \\
\hline & & $\mathrm{I}: 4,0.97-1.38$ & sRPE & $\mathrm{I}: 4,>\mathrm{I} .38$ & RR: $1.27[0.76-2.11]$ \\
\hline & & \multirow[t]{3}{*}{$1: 3,<0.59$} & \multirow[t]{3}{*}{ sRPE } & $\mathrm{I}: 3,0.59-0.97$ & RR: $0.77[0.4 \mid-1.44]$ \\
\hline & & & & I:3. $0.97-1.42$ & RR: $1.17[0.65-2.11]$ \\
\hline & & & & $\mathrm{I}: 3,>1.42$ & RR: $1.47[0.76-2.82]$ \\
\hline & & \multirow[t]{2}{*}{$1: 3,0.59-0.97$} & \multirow[t]{2}{*}{ sRPE } & I:3. $0.97-1.42$ & RR: I.52 [0.92-2.48] \\
\hline & & & & $\mathrm{I}: 3,>1.42$ & RR: $1.90[1.08-3.36]$ \\
\hline & & I:3. $0.97-1.42$ & sRPE & $\mathrm{I}: 3,>1.42$ & RR: $1.25[0.74-2.11]$ \\
\hline & \multirow[t]{6}{*}{ EMWA ACWR } & $<0.80$ & Player Load & $>1.30$ & RR: 3.05 [1.38-6.76]* \\
\hline & & $0.80-1.30$ & Player Load & $>1.30$ & RR: 3.33 [1.35-8.19]* \\
\hline & & $\begin{array}{l}<0.80 \text { and low } \\
21 \text {-day chronic } \\
\text { workload }\end{array}$ & Player Load & $>1.30$ and 21 -day L CW & RR: 14.15 [2.36-84.91]* \\
\hline & & $\begin{array}{l}0.80-1.30 \text { and low } \\
21 \text {-day chronic } \\
\text { workload }\end{array}$ & Player Load & $>1.30$ and 21 -day L CW & RR: $30.67[3.03-310.51]^{*}$ \\
\hline & & $\begin{array}{l}<0.80 \text { and high } \\
21 \text {-day chronic } \\
\text { workload }\end{array}$ & Player Load & $0.80-1.30$ and 21 -day H CW & RR: 2.59 [1.36-4.93]* \\
\hline & & $\begin{array}{l}>1.30 \text { and high } \\
21 \text {-day chronic } \\
\text { workload }\end{array}$ & Player Load & $0.80-1.30$ and 21 -day H CW & RR: $14.52[2.38-88.66]^{*}$ \\
\hline
\end{tabular}


Table 4 (Continued).

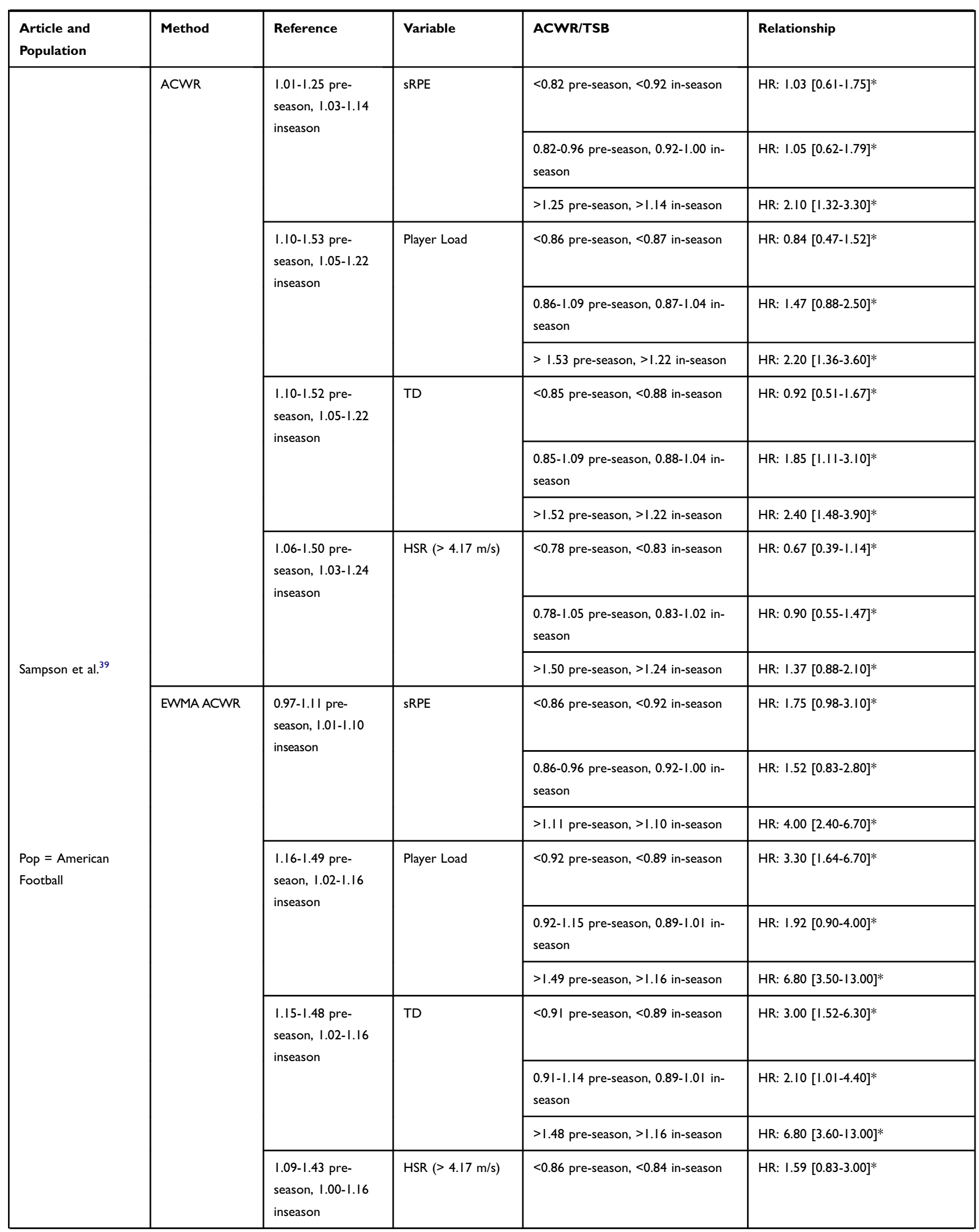

(Continued) 
Table 4 (Continued).

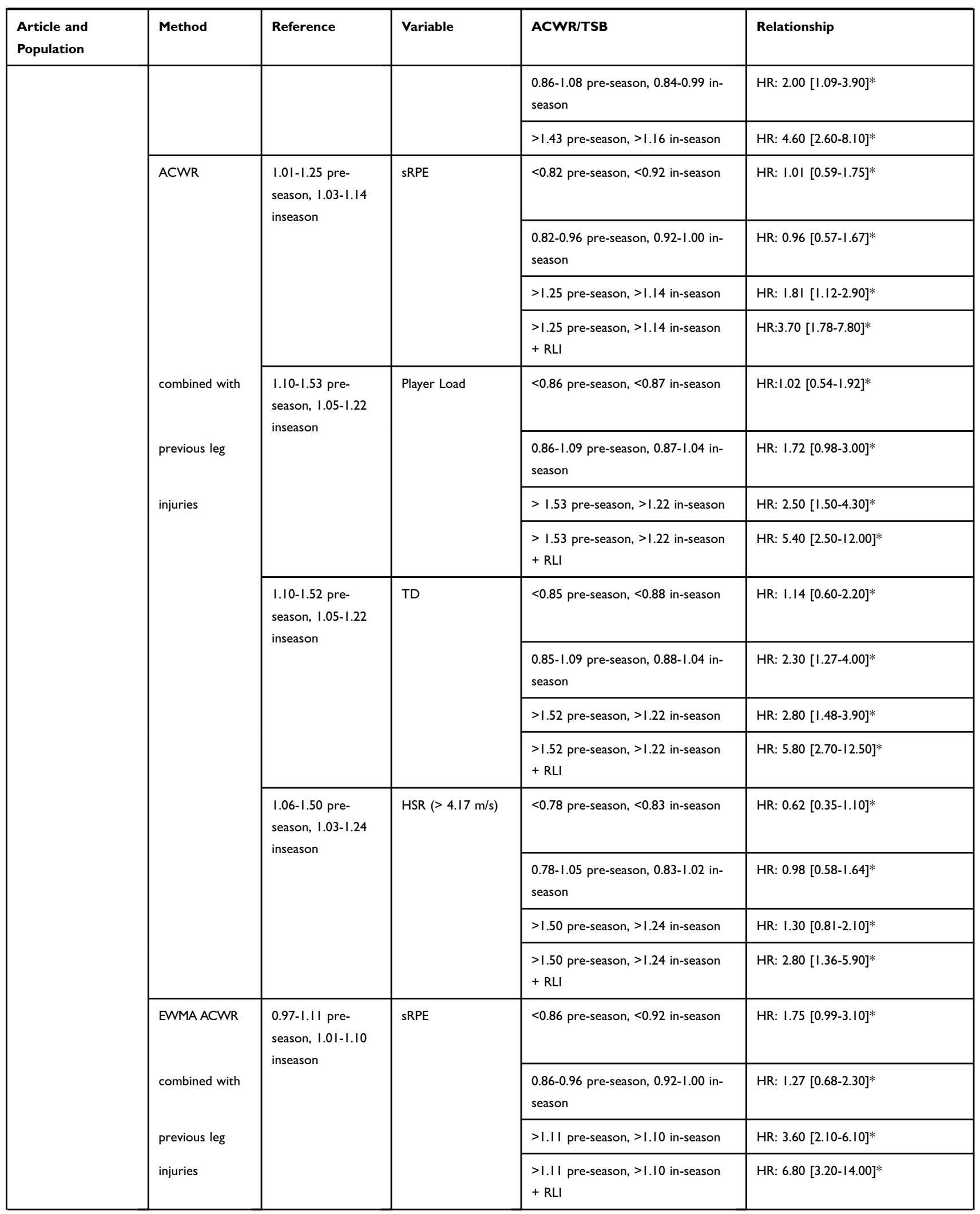

(Continued) 
Table 4 (Continued).

\begin{tabular}{|c|c|c|c|c|c|}
\hline $\begin{array}{l}\text { Article and } \\
\text { Population }\end{array}$ & Method & Reference & Variable & ACWR/TSB & Relationship \\
\hline & & \multirow[t]{4}{*}{$\begin{array}{l}\text { I.16-1.49 pre- } \\
\text { season, I.02-1.16 } \\
\text { in-season }\end{array}$} & \multirow[t]{4}{*}{ Player Load } & $<0.92$ pre-season, $<0.89$ in-season & HR: 3.30 [1.54-7.70]* \\
\hline & & & & $\begin{array}{l}0.92-1.15 \text { pre-season, } 0.89-1.01 \text { in- } \\
\text { season }\end{array}$ & HR: $2.40[1.06-2.60]^{*}$ \\
\hline & & & & $>1.49$ pre-season, $>1.16$ in-season & HR: 8.00 [3.90-17.00]* \\
\hline & & & & $\begin{array}{l}>1.49 \text { pre-season, }>1.16 \text { in-season } \\
+ \text { RLI }\end{array}$ & HR: 16.00 [6.40-40.00]* \\
\hline & & \multirow[t]{4}{*}{$\begin{array}{l}\text { I.I5-I.48 pre- } \\
\text { season, I.02-1.16 } \\
\text { in-season }\end{array}$} & \multirow[t]{4}{*}{ TD } & $<0.91$ pre-season, $<0.89$ in-season & HR: $3.10[1.41-6.70]^{*}$ \\
\hline & & & & $\begin{array}{l}0.91-1.14 \text { pre-season, } 0.89-1.01 \text { in- } \\
\text { season }\end{array}$ & HR: 2.70 [1.19-6.30]* \\
\hline & & & & $>1.48$ pre-season, $>1.16$ in-season & HR: 8.10 [3.90-17.00]* \\
\hline & & & & $\begin{array}{l}>1.48 \text { pre-season, }>1.16 \text { in-season } \\
+ \text { RLI }\end{array}$ & HR: $16.00[6.40-40.00]^{*}$ \\
\hline & & \multirow[t]{4}{*}{$\begin{array}{l}\text { I.09-1.43 pre- } \\
\text { season, I.00-1.16 } \\
\text { in-season }\end{array}$} & \multirow[t]{4}{*}{$\operatorname{HSR}(>4.17 \mathrm{~m} / \mathrm{s})$} & $<0.86$ pre-season, $<0.84$ in-season & HR: $1.67[0.82-3.30]^{*}$ \\
\hline & & & & $\begin{array}{l}0.86-1.08 \text { pre-season, } 0.84-0.99 \text { in- } \\
\text { season }\end{array}$ & HR: 2.10 [1.04-4.00]* \\
\hline & & & & $>1.43$ pre-season, $>1.16$ in-season & HR: 5.10 [2.80-9.40]* \\
\hline & & & & $\begin{array}{l}>1.43 \text { pre-season, }>1.16 \text { in-season } \\
+ \text { RLI }\end{array}$ & HR: $5.70[2.60-12.00]^{*}$ \\
\hline
\end{tabular}

Notes: [], 95\% Confidence interval; [] $]^{\mathrm{a}}, 90 \%$ confidence interval.

Abbreviations: ACWR, acute:chronic workload ratio; HSR, high speed running; MSR, medium speed running; sRPE, session rating of perceived exertion; TSB, training stress balance; TD, total distance; LCW, low chronic workload; HCW, high chronic workload; LSR, low speed running; SD, Sdrint Distance; HRV, heart rate variability; LnRMSSD, log-transformed square root of the mean sum of the squared differences between R-R intervals; RLI, recent leg injury.

was not able to adequately compare variables to find those most related to injury risk, it does appear that the ACWR itself may matter more than the variable studied. For example, utilizing LSR, MSR, and HSR all tended to result in increased injury risked with higher ACWR. Further research will need to be completed to adequately compare variables to each other.

\section{Internal Loads}

High variability also existed in using ILs and ACWRs. While most studies utilized sRPE, reference groups ranged from $1.00^{21}$ to $0.90-1.20 .^{38}$ ACWRs were also variable as one study $^{20}$ examined a range from 0.85 to 1.00 , while another study $^{21}$ analyzed a range from 1.00 to 1.35 . ACWRs were also examined in combination with varying chronic workloads $^{38}$ or varying times in the year. ${ }^{21}$ This makes further systematic analysis of the effectiveness of the
ACWR while using ILs difficult. However, with the "good" quality of included studies, 9,10,20,21,24-26,28-30,37,38 it does appear that utilizing ACWR and sRPE may relate to injury risk in athletic populations. In addition, it was also found that utilizing ACWR and measures of stress, sleep, mood, and energy were significantly related to injury risk. ${ }^{31}$

\section{Limitations}

Several limitations exist in this paper. As noted in the Materials and Methods section, there is potential for search bias, duplication bias, inclusion criteria bias and selector bias. Publication bias might also exist in the current literature, but this was not accounted for in the current study, which may influence the positive findings regarding ACWR and its association with injury risk. Secondly, a metaanalysis may have been able to provide more objective information. This was unable to be completed due to the 


\section{ACWR Combined Effect Size}

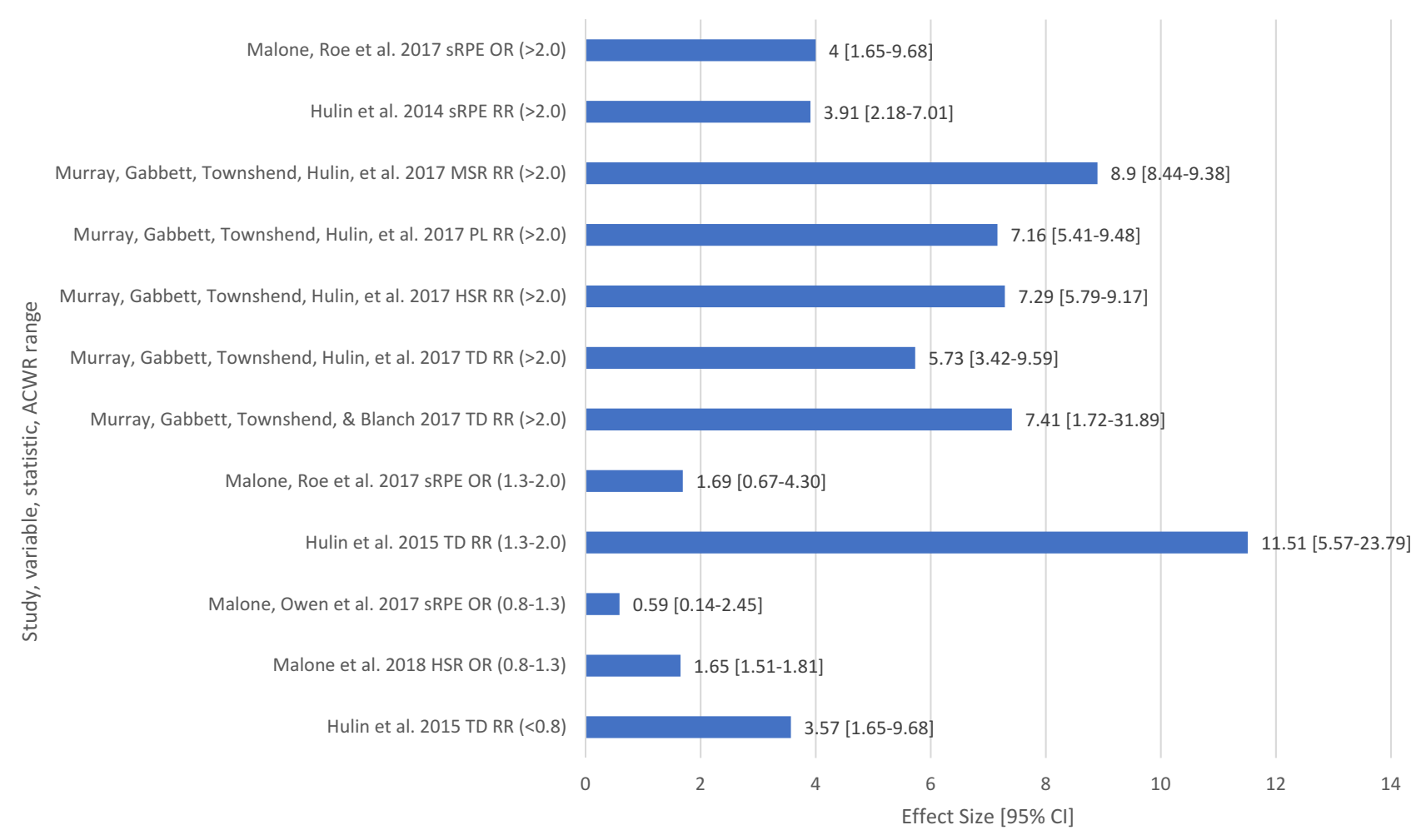

Figure 2 Injury risk combined effect size.

Abbreviations: sRPE, session RPE; OR, odds ratio; RR, relative risk; MSR, medium speed running; PL, player load; HSR, high speed running; TD, total distance.

high variability in the data, as well as difference in statistical variables used (OR, RR, and IRR). Authors were contacted for their data in an attempt to convert all outcomes to one variable, however not enough authors responded. Future research should utilize either one statistical variable or present the sample numbers of athletes injured and non-injured to allow conversion between variables.

Though there appears to be a relationship between both ELs and ILs and injury risk, it is important to note, this relationship may be the result of false correlations due to the acute load being present in both the numerator and denominator ${ }^{42}$ or confounded from an athletic schedule. ${ }^{43}$ Future research will need to be performed to demonstrate the impact of these factors. Until these factors are accounted for in future research, findings should not be interpreted with complete confidence. Clinically, practitioners should realize the ACWR is only part of managing load and injury risk. Other methods, such as week to week changes, or factors, such as sleep, recovery, and nutrition, need to be utilized as part of a comprehensive injury management program. In addition, studies presented in this article also highlighted the importance of fitness ${ }^{23}$ and previous injury on injury risk, ${ }^{36}$ and these factors should not be ignored when attempting to minimize incidence of injuries.

\section{Conclusion}

Given the high variability in studies, little statistical information can be constructed based on the current research. However, the studies included in this review were generally of "good" quality, were completed in multiple countries and encompassed various sports. These studies do suggest that ACWRs follow a parabolic curve when related to injury risk. This is in support of Gabbett, ${ }^{5}$ who stated the lowest injury risk would fall between 0.80 and 1.30 . However, given the potential limitations of ACWR mentioned above, clinicians should not solely rely on this method and use it cautiously. In the future, researchers should collaborate on methodologies or generate set protocols to follow when designing studies with similar reference values, ACWR ranges, and confidence intervals. An example of a set reference group may be the range of $0.80-1.30$, as it may be correlated to the lowest risk of injury. This will potentially result in a more robust field of research, allowing strong conclusions regarding the relationship between ACWR and injury risk. 


\section{Disclosure}

This research was supported by a PhD scholarship for the lead author. The authors have no other funding sources to disclose and report no other conflicts of interest in this work.

\section{References}

1. Hägglund M, Waldén M, Magnusson H, Kristenson K, Bengtsson H, Ekstrand J. Injuries affect team performance negatively in professional football: an 11year follow-up of the UEFA champions league injury study. Br J Sports Med. 2013;47(12):738. doi:10.1136/bjsports-2013-092215

2. Wang D, Chen J, Lai W, Vail J, Rugg CM, Hame SL. Predictive value of the functional movement screen for sports-related injury in NCAA division I athletes. Orthop J Sports Med. 2017;5(3suppl3). doi:10.1177/2325967117S00132

3. Schiff MA, Caine DJ, O'Halloran R. Injury prevention in sports. Am $J$ Lifestyle Med. 2010;4(1):42-64. doi:10.1177/1559827609348446

4. Orchard J, Khan K. Who is to blame for all the football injuries? Blog; British Journal of Sports Medicine. Available at: blogs.bmj. com/bjsm/2012/06/20/who-is-to-blame-for-all-the-football-injuries/. Published June 20, 2012. Accessed September 2019.

5. Gabbett $T$. The training-injury prevention paradox: should athletes be training smarter and harder? $\mathrm{Br} J$ Sports Med. 2016;50:5. doi:10.1136/bjsports-2015-095788

6. Colby M, Dawson B, Heasman J, Rogalski B, Gabbett T. Accelerometer and GPS-derived running loads and injury risk in elite Australian footballers. J Strength Cond Res. 2014;28(8):22442252. doi: $10.1519 /$ JSC. 0000000000000362

7. Soligard T, Schwellnus M, Alonso J-M, et al. How much is too much? (Part 1) International Olympic Committee consensus statement on load in sport and risk of injury. Br J Sports Med. 2016;50 (17):1030-1041. doi:10.1136/bjsports-2016-096581

8. Gabbett T, Hulin B, Blanch P, Whiteley R. High training workloads alone do not cause sports injuries: how you get there is the real issue. $\mathrm{Br}$ J Sports Med. 2016;50(8):444-445. doi:10.1136/bjsports-2015-095567

9. Harrison P, Johnston R. Relationship between training load, fitness, and injury over an Australian rules football preseason. $J$ Strength Cond Res. 2017;31(10):2686-2693. doi:10.1519/JSC.0000000000001829

10. Hulin B, Gabbett T, Blanch P, Chapman P, Bailey D, Orchard J. Spikes in acute workload are associated with increased injury risk in elite cricket fast bowlers. Br J Sports Med. 2014;48(8):708-712. doi:10.1136/bjsports-2013-092524

11. Hulin B, Gabbett T, Lawson D, Caputi P, Sampson J. The acute: chronic workload ratio predicts injury: high chronic workload may decrease injury risk in elite rugby league players. $\mathrm{Br} J$ Sports Med. 2015;50(11):231-236. doi:10.1136/bjsports-2015-094817

12. Tricco AC, Tetzlaff J, Sampson M, et al. Few systematic reviews exist documenting the extent of bias: a systematic review. $J$ Clin Epidemiol. 2008;61(5):422-434. doi:10.1016/j.jclinepi.2007.10.017

13. Moher D, Liberati A, Tetzlaff J, DG A. Preferred reporting items for systematic reviews and metaanalyses: the PRISMA statement. PLoS Med. 2009;6:7. doi:10.1371/journal.pmed.1000097

14. Downs S, Black N. The feasibility of creating a checklist for the assessment of the methodological quality both of randomised and non-randomised studies of health care interventions. J Epidemiol Community Health. 1998;52(6):377. doi:10.1136/jech.52.6.377

15. Handler A, Kennelly J, Peacock N. Reducing Racial/Ethnic Disparities in Reproductive and Perinatal Outcomes. Springer; 2011.

16. Viera AJ, Garrett JM. Understanding interobserver agreement: the kappa statistic. Fam Med. 2005;37(5):360-363.

17. Johnston R, Cahalan R, Bonnett L, et al. Training load and baseline characteristics associated with new injury/pain within an endurance sporting population: a prospective study. Int J Sport Physiol Perform. 2019;14(5):590-597. doi:10.1123/ijspp.2018-0644
18. Hulin B, Gabbett T, Caputi P, Lawson D, Sampson J. Low chronic workload and the acute:chronic workload ratio are more predictive of injury than between-match recovery time: a two-season prospective cohort study in elite rugby league players. Br J Sports Med. 2016;50 (16):1008. doi:10.1136/bjsports-2015-095364

19. Malone S, Owen A, Mendes B, Hughes B, Collins K, Gabbett T. High-speed running and sprinting as an injury risk factor in soccer: can well-developed physical qualities reduce the risk? J Sci Med Sport. 2018;21(3):257-262. doi:10.1016/j.jsams.2017.05.016

20. Malone S, Owen A, Newton M, Mendes B, Collins K, Gabbett T. The acute:chronic workload ratio in relation to injury risk in professional soccer. J Sci Med Sport. 2017;20(6):561-565. doi:10.1016/j. jsams.2016.10.014

21. Malone S, Roe M, Doran D, Gabbett T, Collins K. Protection against spikes in workload with aerobic fitness and playing experience: the role of the acute:chronic workload ratio on injury risk in elite gaelic football. Int J Sports Physiol Perform. 2017;12(3):393. doi:10.1123/ ijspp.2016-0090

22. Murray N, Gabbett T, Townshend A, Hulin B, McLellan C. Individual and combined effects of acute and chronic running loads on injury risk in elite Australian footballers. Scand J Med Sci Sports. 2017;27(9):990-998. doi:10.1111/sms.2017.27.issue-9

23. Malone S, Hughes B, Doran D, Collins K, Gabbett T. Can the workload-injury relationship be moderated by improved strength, speed and repeated-sprint qualities? J Sci Med Sport. 2019;22 (1):29-34. doi:10.1016/j.jsams.2018.01.010

24. Cross M, Williams S, Trewartha G, Kemp S, Stokes K. The influence of in-season training loads on injury risk in professional rugby union. Int J Sports Physiol Perform. 2016;11(3):350. doi:10.1123/ ijspp.2015-0187

25. Jaspers A, Kuyvenhoven J, Staes F, Frencken W, Helsen W, Brink M. Examination of the external and internal load indicators' association with overuse injuries in professional soccer players. J Sci Med Sport. 2018;21(6):579-585. doi:10.1016/j.jsams.2017.10.005

26. McCall A, Jones M, Gelis L, et al. Monitoring loads and non-contact injury during the transition from club to National team prior to an international football tournament: a case study of the 2014 FIFA World Cup and 2015 Asia Cup. J Sci Med Sport. 2018;21(8):800804. doi:10.1016/j.jsams.2017.12.002

27. Murray N, Gabbett T, Townshend A, Blanch P. Calculating acute: chronic workload ratios using exponentially weighted moving averages provides a more sensitive indicator of injury likelihood than rolling averages. $B r \quad J$ Sports Med. 2017;51(9):749. doi:10.1136/bjsports-2016-097152

28. Weiss K, Allen SV, McGuigan M, Whatman CS. The relationship between training load and injury in men's professional basketball. Int J Sport Physiol Perform. 2017;12(9):1238-1242. doi:10.1123/ ijspp.2016-0726

29. Williams S, Booton T, Watson M, Rowland D, Altini M. Heart rate variability is a moderating factor in the workload-injury relationship of competitive CrossFit ${ }^{\mathrm{TM}}$ athletes. J Sports Sci Med. 2017;16(4):443.

30. Colby M, Dawson B, Peeling P, et al. Multivariate modelling of subjective and objective monitoring data improve the detection of non-contact injury risk in elite Australian footballers. $J$ Sci Med Sport. 2017;20(12):1068-1074. doi:10.1016/j.jsams.2017.05.010

31. Hamlin M, Wilkes D, Elliot C, Lizamore C, Kathiravel Y. Monitoring training loads and perceived stress in young elite university athletes. Front Physiol. 2019;10(JAN). doi:10.3389/fphys.2019.00034

32. Colby M, Dawson B, Peeling P, et al. Improvement of prediction of noncontact injury in elite australian footballers with repeated exposure to established high-risk workload scenarios. Int J Sports Physiol Perform. 2018;13(9):1130-1135. doi:10.1123/ijspp.2017-0696

33. Raya-González J, Nakamura FY, Castillo D, Yanci J, Fanchini M. Determining the relationship between internal load markers and noncontact injuries in young elite soccer players. Int J Sport Physiol Perform. 2019;14(4):421-425. doi:10.1123/ijspp.2018-0466 
34. Cummins C, Welch M, Inkster B, et al. Modelling the relationships between volume, intensity and injury-risk in professional rugby league players. J Sci Med Sport. 2019;22(6):653-660. doi:10.1016/j. jsams.2018.11.028

35. Delecroix B, McCall A, Dawson B, Berthoin S, Dupont G. Workload and non-contact injury incidence in elite football players competing in European leagues. Eur j Sport Sci. 2018;18(9):1280-1287. doi:10.1080/17461391.2018.1477994

36. Esmaeili A, Hopkins W, Stewart A, Elias G, Lazarus B, Aughey R. The individual and combined effects of multiple factors on the risk of soft tissue non-contact injuries in elite team sport athletes. Front Physiol. 2018;9(SEP). doi:10.3389/fphys.2018.01280

37. Carey D, Blanch P, Ong K-L, Crossley K, Crow J, Morris M. Training loads and injury risk in Australian football — differing acute:chronic workload ratios influence match injury risk. Br J Sports Med. 2017;51(16):1215. doi:10.1136/bjsports-2016-096309

38. Stares J, Dawson B, Peeling P, et al. Identifying high risk loading conditions for in-season injury in elite Australian football players. $J$ Sci Med Sport. 2018;21(1):46-51. doi:10.1016/j.jsams.2017.05.012
39. Sampson JA, Murray A, Williams S, et al. Injury risk-workload associations in NCAA American college football. J Sci Med Sport. 2018;21(12):1215-1220. doi:10.1016/j.jsams.2018.05.019

40. McCall A, Dupont G, Ekstrand J. Internal workload and non-contact injury: a one-season study of five teams from the UEFA elite club injury study. Br J Sports Med. 2018;52(23):1517-1522. doi:10.1136/ bjsports-2017-098473

41. Bourdon P, Cardinale M, Murray A, et al. Monitoring athlete training loads: consensus statement. Int J Sports Physiol Perf. 2017;12(Suppl 2):S2-161-S162-170.

42. Lolli L, Batterham A, Hawkins R, et al. Mathematical coupling causes spurious correlation within the conventional acute-to-chronic workload ratio calculations. Br J Sports Med. 2017;53:921-922.

43. Bornn L, Ward P, Norman D. Training schedule confounds the relationship between acute:chronic workload ratio and injury. MIT Sloan Sports Analystics Conference; 2019; Boston, MA.

\section{Publish your work in this journal}

Open Access Journal of Sports Medicine is an international, peerreviewed, open access journal publishing original research, reports, reviews and commentaries on all areas of sports medicine. The manuscript management system is completely online and includes a very quick and fair peer-review system. Visit http://www.dovepress. com/testimonials.php to read real quotes from published authors. 